\title{
Preparation of alginate hydrogel microparticles by gelation introducing cross-linkers using droplet-based microfluidics: a review of methods
}

\author{
Cheng Zhang, Romain Grossier, Nadine Candoni and Stéphane Veesler ${ }^{*}$ (i)
}

\begin{abstract}
This review examines the preparation of alginate hydrogel microparticles by using droplet-based microfluidics, a technique widely employed for its ease of use and excellent control of physicochemical properties, with narrow size distribution. The gelation of alginate is realized "on-chip" and/or "off-chip", depending on where cross-linkers are introduced. Various strategies are described and compared. Microparticle properties such as size, shape, concentration, stability and mechanical properties are discussed. Finally, we consider future perspectives for the preparation of hydrogel microparticles and their potential applications.
\end{abstract}

Keywords: Alginate, Hydrogel, Microparticle, Crosslinking, Droplet-based microfluidics

\section{Introduction}

Hydrogel microparticles are widely used today, especially in biological and pharmaceutical applications. They are usually used as a matrix to encapsulate bioactive agents such as drugs, proteins, cells, etc. [2, 12, 30] in applications like drug delivery [1], cell culture and tissue engineering [49]. In addition, fluorescence-encoded hydrogel microparticles are extensively employed in multiplex bioassays $[42,62,64]$. Another important use is as cell-mimicking microparticles with similar size, shape, deformability and mechanical properties [18, 32, 59]. Hydrogels can be made of various biopolymers such as gelatine, agarose, alginate, pectin, etc. Alginate stands out because of its low cost, non-toxicity and ease of crosslinking [25].

With the increasing interest in alginate hydrogel microparticles, various preparation methods have been reported in the literature [27], including conventional

\footnotetext{
* Correspondence: veesler@cinam.univ-mrs.fr

CNRS, Aix-Marseille Université, CINaM (Centre Interdisciplinaire de Nanosciences de Marseille), Campus de Luminy, Case 913, F-13288 Marseille Cedex 09, France
}

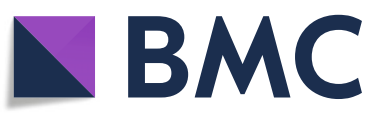

emulsification [8], spray-drying [40], extrusion dripping $[4,24]$, microfluidics $[39,56,60]$ and soft lithography [36]. The huge diversity of techniques and strategies can make it confusing to choose the right method. The present review focuses on a microparticle-producing technique widely used for its efficacy in controlling physicochemical properties: droplet-based microfluidics. After basic recalls on alginate chemistry and dropletbased microfluidics, the various strategies applied within this technique and the properties of the microparticles obtained are described in this review. We expect this paper useful for researchers who want to know what is possible to do with droplet-based microfluidics for the preparation of alginate hydrogel microparticles by introducing cross-linkers.

\section{Alginate hydrogel microparticles}

Hydrogels are described as hydrophilic polymeric networks which can absorb and retain large amounts of water within the structure. The hydrogel network is formed by polymer crosslinking. When crosslinking is

(c) The Author(s). 2021 Open Access This article is licensed under a Creative Commons Attribution 4.0 International License, which permits use, sharing, adaptation, distribution and reproduction in any medium or format, as long as you give appropriate credit to the original author(s) and the source, provide a link to the Creative Commons licence, and indicate if changes were made. The images or other third party material in this article are included in the article's Creative Commons licence, unless indicated otherwise in a credit line to the material. If material is not included in the article's Creative Commons licence and your intended use is not permitted by statutory regulation or exceeds the permitted use, you will need to obtain permission directly from the copyright holder. To view a copy of this licence, visit http://creativecommons.org/licenses/by/4.0/ The Creative Commons Public Domain Dedication waiver (http://creativecommons.org/publicdomain/zero/1.0/) applies to the data made available in this article, unless otherwise stated in a credit line to the data. 
realized by molecular entanglement, ionic, $\mathrm{H}$-bonding or hydrophobic forces, hydrogels are called physical or reversible gels. Otherwise, when covalent forces intervene, they are called chemical or permanent gels $[6,19]$.

\section{Alginate}

Alginate is a natural polysaccharide. Although it can also be synthesized by several bacteria, all the commercially available alginate is produced from the extraction of brown algae [11]. Alginate is widely used in the biomedical field because it is biocompatible and non-toxic [25].

Sodium alginate ( $\mathrm{Na}$-alginate) is the most widely used alginate salt. It dissolves in water to a viscous solution. Alginate is a linear copolymer containing $\beta$-D-mannuronate $(\mathrm{M})$ and $\alpha$-L-guluronate $(\mathrm{G})$ residues (Fig. 1).

\section{Gelation of alginate}

Alginate hydrogel is produced by gelation which is caused by covalent [14] or ionic crosslinking [15, 51]. Ionic crosslinking is more commonly used because of its simplicity and mild conditions. It can be carried out at room temperature or up to $100^{\circ} \mathrm{C}$, usually with divalent cations as cross-linkers. Calcium chloride is the most widely used [25], due to its non-toxicity [1] and availability.

Only G-blocks (Fig. 1a) made of consecutive G residues can participate in ionic crosslinking because of their favorable spatial structure $[15,25]$. Ionic crosslinking of alginate is described by the "egg-box" model [16] (Fig. 2).

In this review, we present various two-step methods of producing alginate hydrogel microparticles. First, sodium alginate droplets are generated using droplet-based microfluidics. Second, internal or external gelation transforms droplets into alginate hydrogel microparticles via different strategies. It should be noted that only ionic crosslinking is discussed herein. In internal gelation, the cross-linkers are inside the alginate droplet whereas in external gelation, the cross-linkers come from outside the alginate droplet.

\section{Droplet-based microfluidics}

\section{Principle of droplet generation}

Microfluidics is a technique used to manipulate fluids in channels of micrometric dimensions. Fluids are mixed by adding junctions that connect the channels. When immiscible or partially miscible fluids are mixed in the junction, microdroplets can be generated: this is called droplet-based microfluidics.

The principle is similar to that of conventional emulsification, which consists of blending two immiscible liquids. The advantage of droplet-based microfluidics is monodispersity and repeatability of droplets due to precise control over experimental conditions such as channel geometry, flow rates and viscosities of fluids, etc. [41, 46]. Furthermore, monodisperse droplets can be generated without using surfactant $[28,48,59]$, which is impossible with conventional emulsification.

The droplets generated in droplet-based microfluidics can serve as microreactors to carry out physical, chemical or biological reactions [65]. Being small (nL to $\mu \mathrm{L}$ volume), they require a small quantity of reactants. As droplet composition can be made identical, numerous identical experiments can be performed, enabling a reliable statistical approach to data.

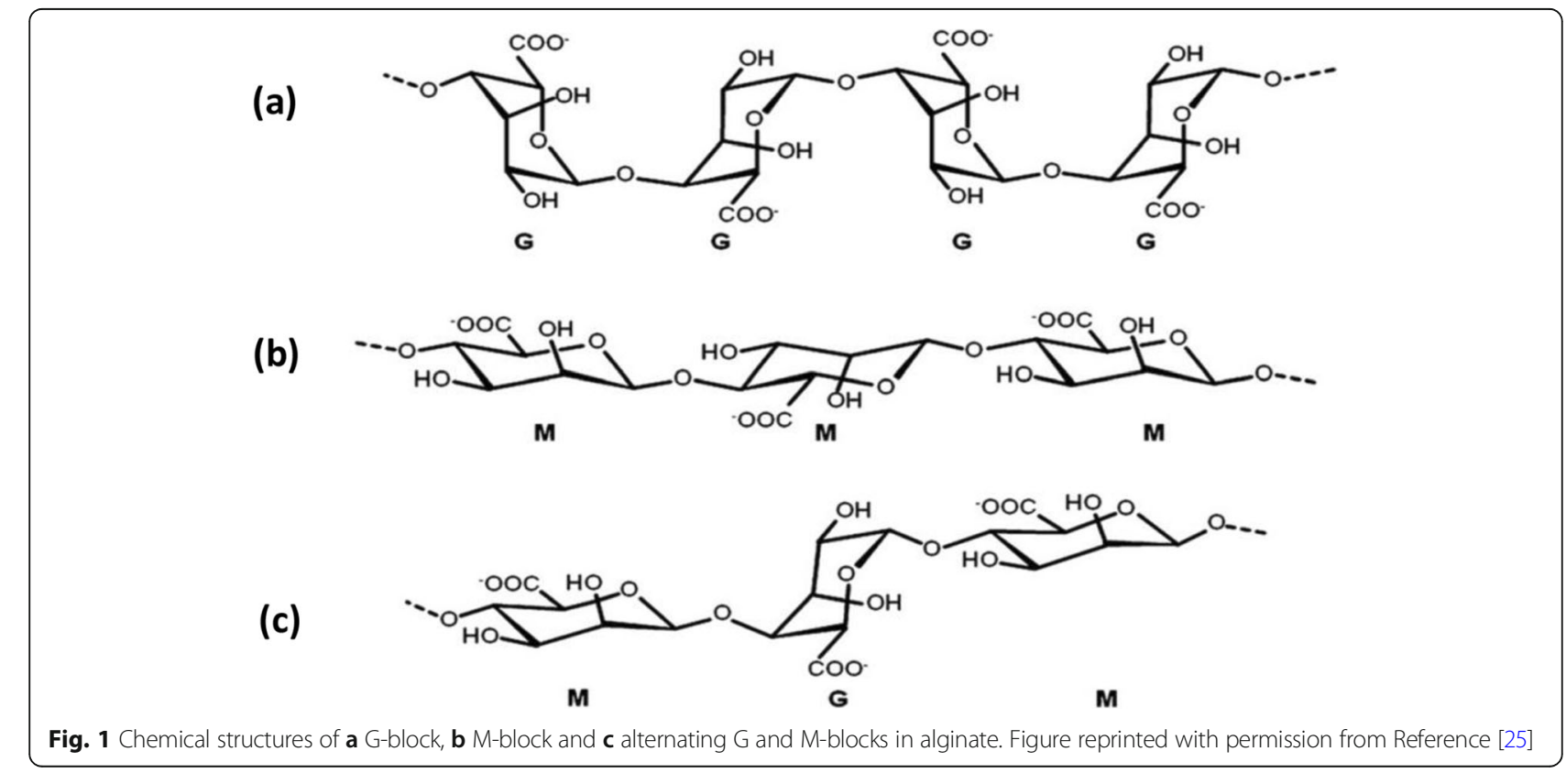




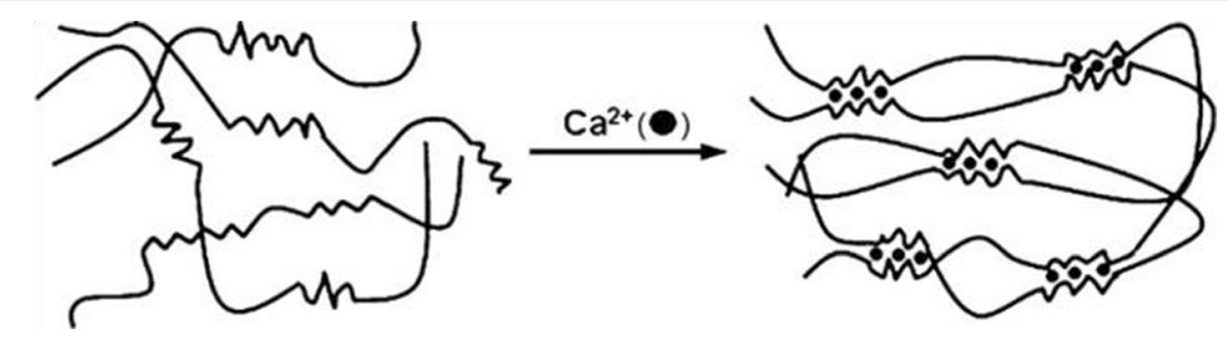

Fig. 2 Schematic illustration of the "egg-box" model describing the ionic crosslinking of alginate by calcium cations. Figure reprinted with permission from Reference [26]

\section{Flow properties}

In droplet-based microfluidics, a continuous fluid and a dispersed fluid are injected separately and then mixed in a junction. Fluids are Newtonian and droplets of the dispersed fluid (D) are generated in the flow of the continuous fluid (C). The physicochemical properties influencing droplet formation are density, dynamic viscosity, surface tension between the continuous and the dispersed fluids, velocity of the flows and characteristic dimensions of the microfluidic system, such as the diameter of channels (w) for cylindrical microfluidic systems. Based on these properties, fluid dynamics is characterized as follows:

1- Inertial forces and viscous forces are compared through the Reynolds number, calculated using the continuous fluid properties: density $\left(\rho_{C}\right)$, dynamic viscosity $\left(\mu_{C}\right)$ and flow velocity $\left(v_{C}\right)$.

$$
\operatorname{Re}=\frac{\rho_{C} \times v_{C} \times \mathrm{w}}{\mu_{C}}
$$

Typically for microfluidics, values of Re are lower than 1: the flow is laminar and the effect of inertia can be ignored. Thus, the average velocity $\mathrm{v}$ of a flow is evaluated from its volumetric flow rate $\mathrm{Q}$ and $\mathrm{w}$ as follows:

$$
v=\frac{Q}{\pi(\mathrm{w} / 2)^{2}}
$$

2- The generation of droplets in a microfluidic junction creates a free interface between the two fluids, characterized by the interfacial energy $\gamma_{\mathrm{CD}}$. The corresponding capillary effects are in competition with gravity effects. The length above which gravity effects dominate capillary effects is the capillary length $l_{c}$ :

$$
l_{c}=\sqrt{\frac{\gamma_{\mathrm{CD}}}{\Delta \rho \times g}}
$$

with $g$ the gravity acceleration and $\Delta \rho$ the difference in density between the two fluids. For instance, with fluorinated oil FC70 as the continuous fluid and ethanol as the dispersed fluid, $l_{c}$ is equal to $2.4 \mathrm{~mm}$ [63]. Hence gravity does not influence the deformation of the interfaces in millimetric or sub-millimetric channels.

3- Shear stress and interfacial energy are compared through the capillary number $\mathrm{Ca}$. When generating droplets of a dispersed fluid in a continuous fluid, $\mathrm{Ca}$ is usually calculated using $v_{C}$ and $\mu_{\mathrm{C}}$ of the continuous fluid, and $\gamma_{\mathrm{CD}}$ of the interface between the continuous and the dispersed fluid:

$$
\mathrm{Ca}=\frac{\mu_{C} \times v_{C}}{\gamma_{\mathrm{CD}}}
$$

\section{Microfluidic geometry}

Microfluidic devices can be in the form of either chips with microchannels and junctions produced by soft lithography, or an assembly of capillaries and junctions [37]. In terms of materials, polydimethylsiloxane (PDMS) is the most commonly used for microfluidic chips $[28,60]$. For capillaries, both glass $[5,20]$ and fluoropolymer can be used $[48,59]$.

The channel geometry of a microfluidic device influences droplet generation. Three frequently used geometries are "cross-flow", "co-flow" and "flow-focusing" (Fig. 3).

\section{Cross-flowing}

For cross-flowing geometry, continuous fluid and dispersed fluid mix with an angle $\boldsymbol{\theta}\left(0^{\circ}<\boldsymbol{\theta} \leq 180^{\circ}\right)$ at the 


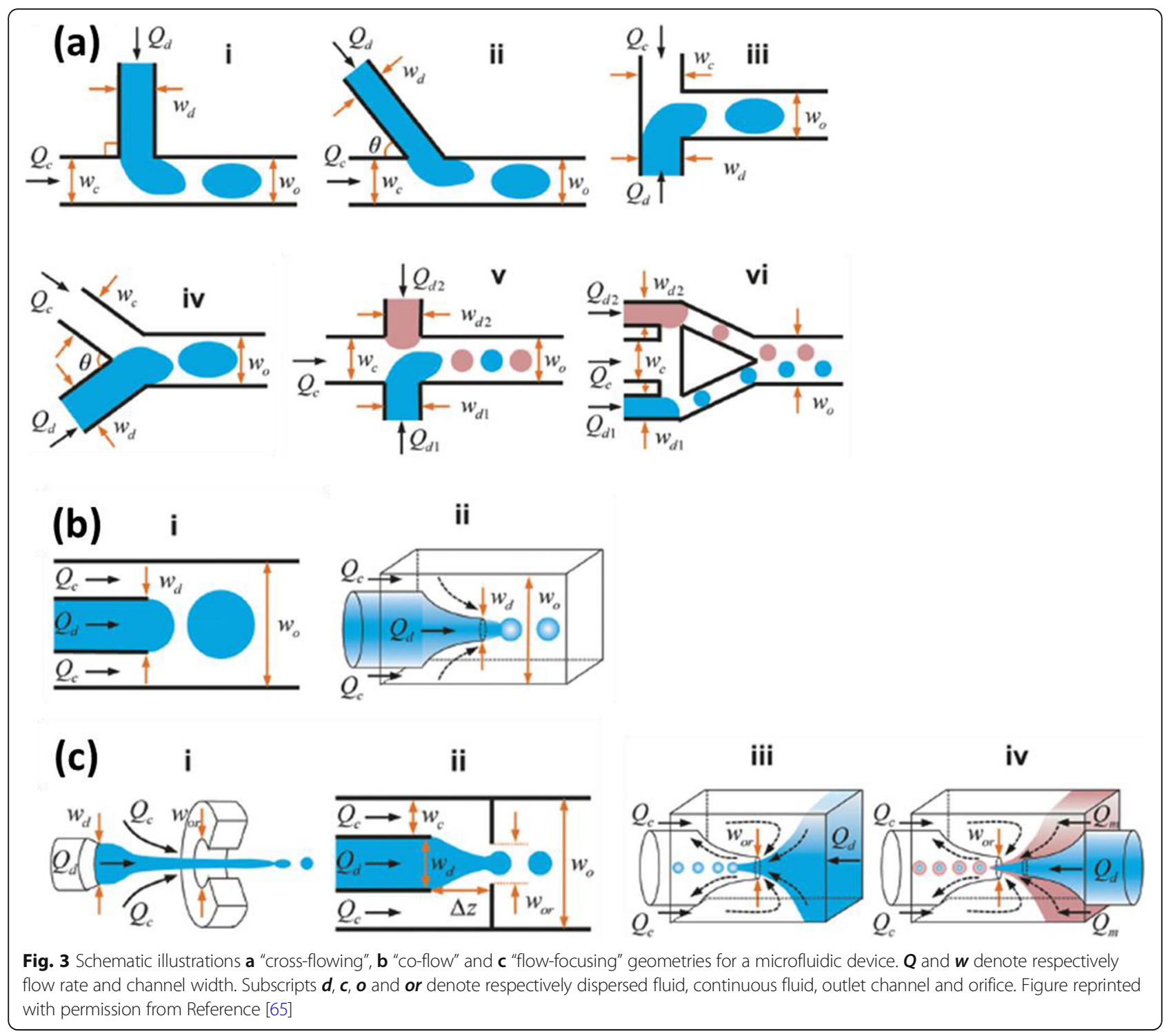

junction (Fig. 3a). Where the two fluids meet, first an interface is formed due to the immiscibility of the two fluids. Shear force then pushes the head of the dispersed fluid into the continuous fluid until a part breaks off: the droplet is formed. Then it circulates in the channel of the continuous fluid [46].

Cross-flowing geometry is often called T-junction geometry, where two fluids flow orthogonally (Fig. 3a i). However, other shapes of junctions can also be used, such as a junction with an arbitrary angle $\boldsymbol{\theta}$ (Fig. 3a ii), or a Y-shaped junction (Fig. 3a iv). For two fluids facing each other $\left(\boldsymbol{\theta}=180^{\circ}\right.$, Fig. 3a iii), the geometry is called "head-on". A combination of two junctions (Fig. 3a v, vi) can also be used to introduce two different dispersed fluids and one continuous fluid. Cross-flowing geometry is widely used due to its ease of assembly and handling $[41,65]$.

\section{Flow-focusing}

For co-flow geometry, two immiscible fluids flow in two concentric channels (Fig. 3b). Droplets are formed at the outlet of the inner channel. Flow-focusing geometry is actually similar to co-flow geometry. The distinction presented in the literature is somewhat ambiguous [65], leading some to consider flow-focusing as a special coflow geometry [41]. For flow-focusing geometry (Fig. 3c), two immiscible fluids are focused through an orifice, which allows smaller droplets to be generated than with co-flow geometry.

\section{Droplet generation regime}

For each geometry, droplets can be generated following three different break-off mechanisms. The transition from one mechanism to another can be achieved by varying capillary 
numbers $\mathrm{Ca}$ [65]. Figure 4 shows an example of three mechanisms for a cross-flowing geometry.

\section{Squeezing}

As Fig. 4a shows, as it is injected into the principal channel, the dispersed fluid is pushed forward by the continuous fluid. A thin "neck" is thus formed. Because the continuous fluid applies weak shear force, the forming droplet reaches the opposing channel wall without breaking off. The neck becomes thinner until it breaks, so that a plug-shaped droplet confined by channel wall is formed. Squeezing mechanism appears when $\mathrm{Ca}$ is low $(\mathrm{Ca} \leq 0.01)[10]$.

\section{Dripping}

As Fig. 4b shows, the shear force applied is now higher. The forming droplet breaks off before touching the opposing channel wall. A spherical droplet is formed with a diameter smaller than that of the channel. This dripping mechanism appears at a higher $\mathrm{Ca}(\mathrm{Ca} \geq 0.02)[10]$.

\section{Jetting}

As Fig. 4c shows, a liquid jet is emitted from the dispersed fluid channel. It flows and remains attached to the channel wall, due to a strong shear force from the continuous fluid [9]. The jet breaks up into droplets at the end because of Rayleigh-Plateau instability [65]. Droplets of polydisperse sizes are formed. This jetting mechanism appears at the highest $\mathrm{Ca}(\mathrm{Ca} \approx 0.2)$.

\section{Gelation}

Internal gelation

For internal gelation, cross-linkers come from inside the alginate droplets and are either soluble or insoluble/ slightly soluble in water. In this approach, cross-linkers are always introduced in the microfluidic device.

\section{Water-soluble cross-linkers}

With water-soluble cross-linkers such as barium chloride $\left(\mathrm{BaCl}_{2}\right)$ and calcium chloride $\left(\mathrm{CaCl}_{2}\right)$, alginate is crosslinked directly at the interior of droplets. These agents can be mixed with $\mathrm{Na}$-alginate before or after droplet generation.

Mixing cross-linkers before droplet generation A first category of strategies is based on mixing water-soluble cross-linkers with $\mathrm{Na}$-alginate before droplet generation. The cross-linkers used in these studies are $\mathrm{BaCl}_{2}$ and $\mathrm{CaCl}_{2}$; these strategies are summarized in Table 1.

Trivedi et al. worked on cell encapsulation by alginate hydrogel microparticles [48]. For the preparation of microparticles, an aqueous solution of cell-containing $\mathrm{Na}$ alginate (1\%) and a solution of $\mathrm{BaCl}_{2}(50 \mathrm{mM})$ were injected into the capillary and mixed via a Y-shaped junction. At the exit from the mixing region, highly viscous silicone oil $(10 \mathrm{cSt})$ without surfactant was injected by flow-focusing in order to generate droplets. However, the mixing of Na-alginate and barium cations triggered ionic crosslinking, causing gelation in the mixing region which impacted droplet generation. Finally, instead of generating droplets as expected, a jet of gel was (a)
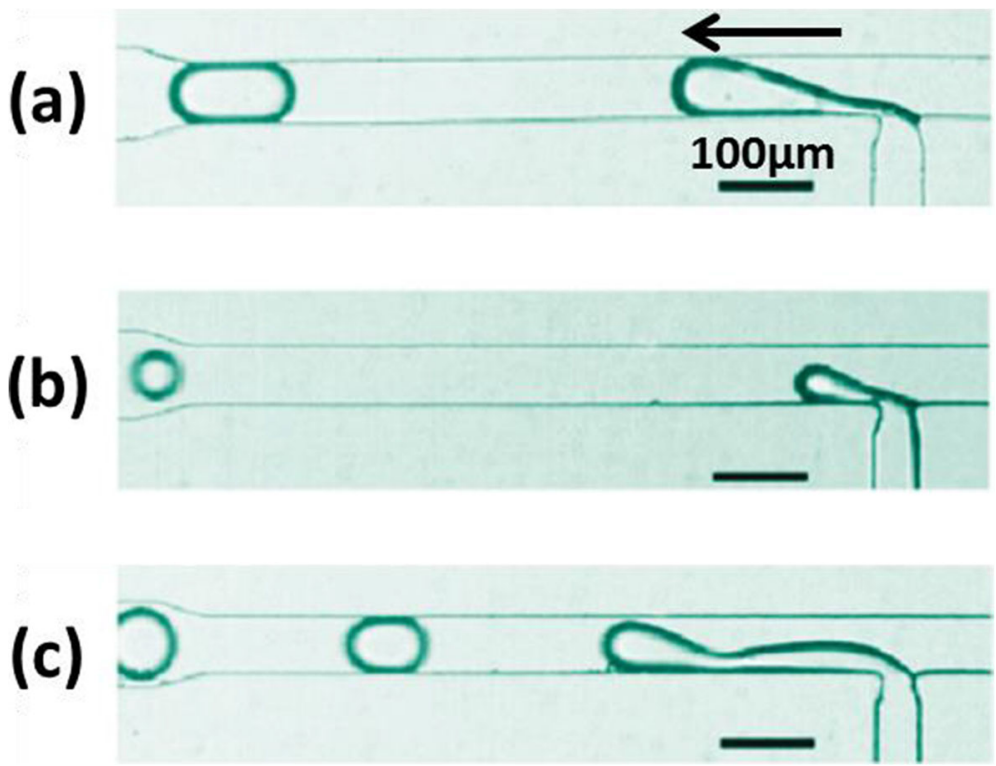

Fig. 4 Three break-off mechanisms of droplet generation with a cross-flowing geometry: a squeezing, $\mathbf{b}$ dripping and $\mathbf{c}$ jetting. The arrow indicates the droplet flow direction. Figure reprinted with permission from Reference [57]. Copyright 2010 American Chemical Society 
Table 1 Internal gelation with water-soluble cross-linkers: mixing cross-linkers with Na-alginate before droplet generation

\begin{tabular}{|c|c|c|c|c|c|c|}
\hline References & & $\begin{array}{l}\text { Trivedi et al., } \\
2009 \text { [48] }\end{array}$ & $\begin{array}{l}\text { Zhang et al., } \\
2006[60]\end{array}$ & $\begin{array}{l}\text { Rondeau and } \\
\text { Cooper-White, } 2008 \\
\text { [39] }\end{array}$ & Present review & Present review \\
\hline \multirow[t]{5}{*}{ Droplet generation } & $\begin{array}{l}\text { Concentration of } \\
\text { Na-alginate }\end{array}$ & $1 \mathrm{wt} \%$ & 0.5 wt $\%$ & $0.5 w t \%$ & $0.06 w t \%$ & 0.006 wt $\%$ \\
\hline & Continuous fluid & Silicone oil & Mineral oil & $\mathrm{DMC}^{\mathrm{a}}$ & $\mathrm{DMC}^{\mathrm{a}}$ & $\mathrm{DMC}^{\mathrm{a}}$ \\
\hline & Use of surfactant & NO & Span 80 & Not mentioned & NO & NO \\
\hline & Geometry & Flow-focusing & Flow-focusing & Flow-focusing & Cross-flowing & Cross-flowing \\
\hline & $\begin{array}{l}\text { Microfluidic } \\
\text { material }\end{array}$ & $\begin{array}{l}\text { Fluoropolymer } \\
\text { tubing and } \\
\text { junctions }\end{array}$ & PDMS chip & PDMS chip & $\begin{array}{l}\text { Fluoropolymer } \\
\text { tubing and } \\
\text { junctions }\end{array}$ & $\begin{array}{l}\text { Fluoropolymer } \\
\text { tubing and } \\
\text { junctions }\end{array}$ \\
\hline \multirow{3}{*}{$\begin{array}{l}\text { Internal gelation by } \\
\text { mixing } \\
\text { Na-alginate and } \\
\text { water-soluble cross- } \\
\text { linker }\end{array}$} & Cross-linker & $\mathrm{BaCl}_{2}(50 \mathrm{mM})$ & $\begin{array}{l}\mathrm{CaCl}_{2}(0.1 \\
\text { wt\%) }\end{array}$ & $\mathrm{CaCl}_{2}(0.25 \mathrm{wt} \%)$ & $\mathrm{CaCl}_{2}(0.06$ wt $\%)$ & $\mathrm{CaCl}_{2}(0.002 \mathrm{wt} \%)$ \\
\hline & Geometry & Flow-focusing & Cross-flowing & Flow-focusing & - & Cross-flowing \\
\hline & Mixing & $\begin{array}{l}\text { Before droplet } \\
\text { generation }\end{array}$ & $\begin{array}{l}\text { During } \\
\text { droplet } \\
\text { generation }\end{array}$ & $\begin{array}{l}\text { Before droplet } \\
\text { generation }\end{array}$ & $\begin{array}{l}\text { Off-line, before } \\
\text { droplet generation }\end{array}$ & $\begin{array}{l}\text { During droplet } \\
\text { generation }\end{array}$ \\
\hline
\end{tabular}

${ }^{\mathrm{a} C o n t i n u o u s ~ a n d ~ d i s p e r s e d ~ f l u i d s ~ p a r t i a l l y ~ m i s c i b l e ~-~ D M C ~(D i m e t h y l ~ C a r b o n a t e) ~}$

produced with a partially formed droplet head and a long gelatinous tail.

To deal with this issue, the mixing region can be reduced before droplet generation, as Zhang et al. did [60] Using a 5-channel microfluidic device, they mixed $\mathrm{Na}$ alginate fluid (0.5 wt\%), $\mathrm{CaCl}_{2}$ fluids $(0.1 \mathrm{wt} \%)$ and mineral oil fluids with a surfactant (Span 80, no concentration mentioned) as shown in Fig. 5. Droplets were generated by co-flow. However, instead of producing discrete droplets, a line of knots connected with each other was formed. This phenomenon persisted with a wide range of flow rates of oil due to viscosity which increased instantly when $\mathrm{Na}$-alginate and $\mathrm{CaCl}_{2}$ were mixed, because of rapid gelation. It was therefore impossible to generate droplets at the junction, despite the use of surfactant.
The problem can be solved by using low concentrations of Na-alginate and $\mathrm{CaCl}_{2}$ solutions. In this case, gelation proceeds after droplet generation and is enhanced by using partially miscible fluids. Rondeau and Cooper-White used Dimethyl carbonate (DMC) as the continuous fluid [39] (Fig. 6). The solubility of water in $\mathrm{DMC}$ is about $3 \mathrm{wt} \%$ at room temperature [43]. Aqueous solutions of Na-alginate $(0.5 \mathrm{wt} \%)$ and $\mathrm{CaCl}_{2}(0.25 \mathrm{wt} \%)$ were injected respectively from inlets $\mathrm{A}$ and $\mathrm{B}$ (Fig. 6a). After a short pre-gelation channel, DMC was injected from inlet $\mathrm{C}$. Na-alginate $/ \mathrm{CaCl}_{2}$ droplets were generated in DMC (no mention of surfactant usage) by flowfocusing. Along the serpentine channel, because of the low solubility of water in DMC, water diffused gradually from droplets into DMC, causing the shrinkage of droplets along the channel. Internal gelation occurred at the

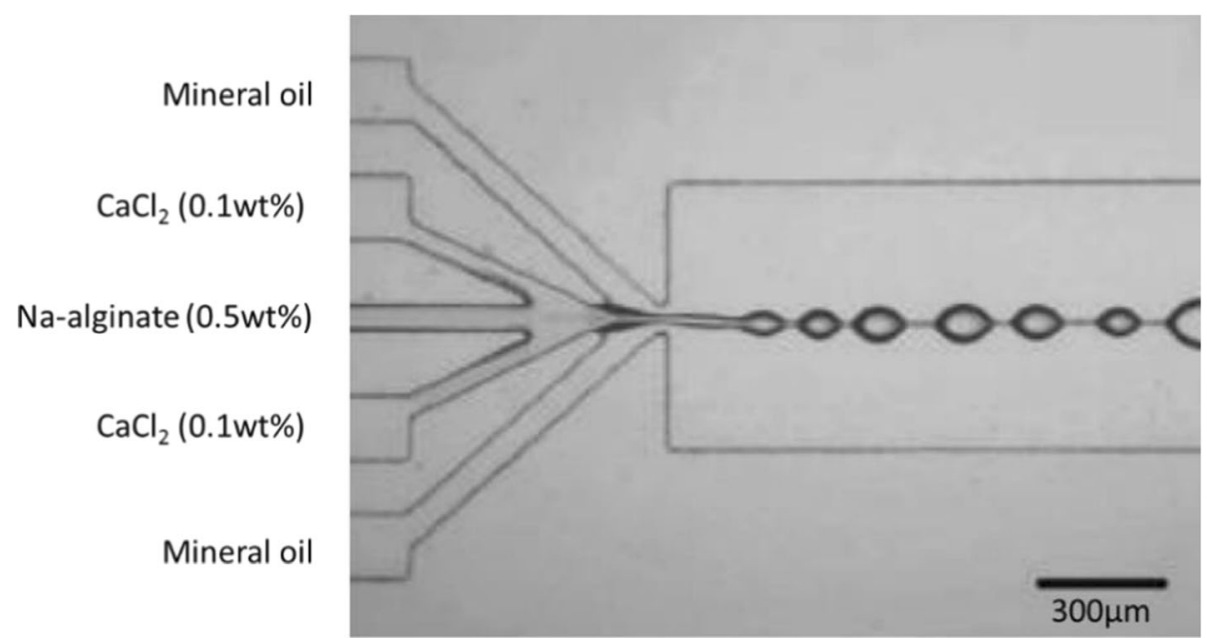

Fig. 5 Image of connected knots formed after mixing Na-alginate and $\mathrm{CaCl}_{2}$ solutions in mineral oil with surfactant, in a PDMS-based microfluidic chip. Figure reprinted with permission from Reference [60]. Copyright 2006 American Chemical Society 


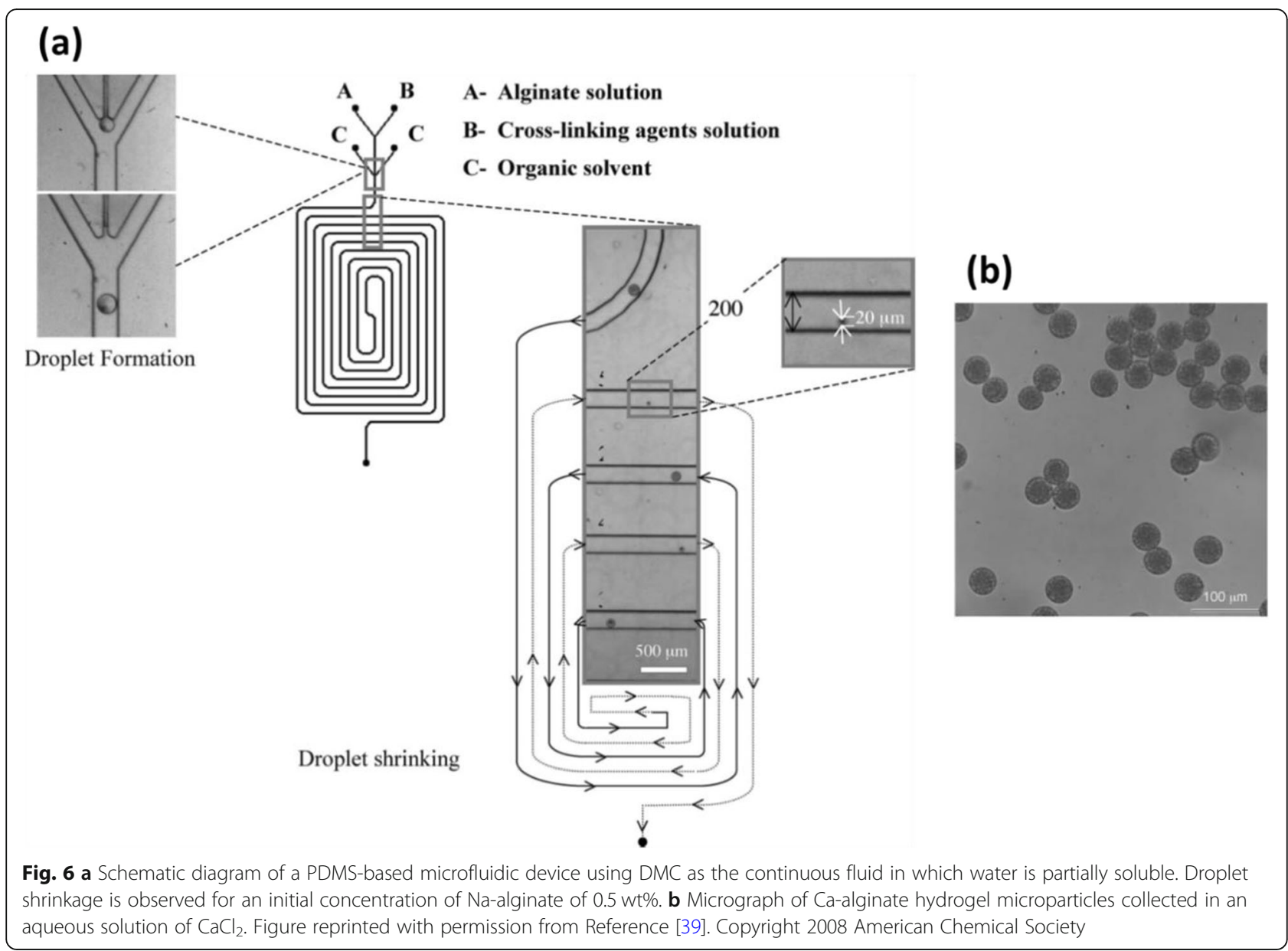

same time. Microparticles with a diameter of $20 \mu \mathrm{m}$ were observed at the outlet of the channel and collected in an aqueous solution of $\mathrm{CaCl}_{2}(2 \mathrm{~N})$ to reinforce the gelation (Fig. 6b). The diameter of Ca-alginate hydrogel microparticles was influenced by the experimental parameters such as the initial concentration of Na-alginate, flow rates of fluids and channel size. To be precise, smaller $\mathrm{Ca}$-alginate hydrogel microparticles can be obtained by using a less concentrated $\mathrm{Na}$-alginate solution, a higher flow rate ratio between the continuous fluid and the dispersed fluid, or a narrower channel. However, DMC is also slightly soluble in water, with a solubility of 12.7 wt $\%$ at $20^{\circ} \mathrm{C}$ [43]. Thus, during diffusion of water from droplets into DMC, DMC can also diffuse into droplets. This means that, after gelation, DMC can be captured inside alginate hydrogel microparticles. Additional work measuring the amount of DMC residue within microparticles could open the way to further applications.

Following the work of Rondeau and Cooper-White, we tested, in a T-junction (Fig. 7), the direct generation of

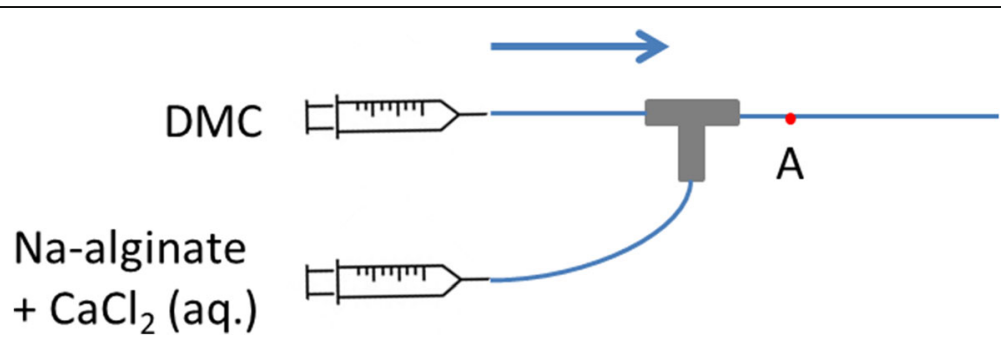

Fig. 7 Schematic diagram of the generation of droplets of Ca-alginate with DMC as the continuous fluid and an aqueous mixed solution of Naalginate and $\mathrm{CaCl}_{2}$ as the dispersed fluid. The device is composed of polyether ether ketone (PEEK) junctions and Teflon-like tubing (IDEX Health and Science). The arrow indicates the flow direction 
droplets of Ca-alginate in DMC without surfactant from a mixture of more diluted $\mathrm{Na}$-alginate and $\mathrm{CaCl}_{2}$ solutions (both at $0.06 \mathrm{wt} \%$ after mixing). However, this solution was not clear and local gelation was occasionally observed with the naked eye. When these gels entered the channel, droplets were generated in a discontinuous way. This indicates that, even at very low concentrations, thorough mixing of $\mathrm{Na}$-alginate and $\mathrm{CaCl}_{2}$ solutions leads to gelation, disturbing droplet generation.

In a microfluidic device (Fig. 8) of similar design to Zhang et al. [59], we were able to generate discrete droplets by using extremely diluted solutions of $\mathrm{Na}$-alginate (0.006 wt\%) and $\mathrm{CaCl}_{2}(0.002 \mathrm{wt} \%)$. The continuous fluid was DMC without surfactant. Droplets were observed after the cross-junction (point A in Fig. 8a). Since they were relatively close to each other in the channel, causing coalescence at the outlet (point B in Fig. 8a), a second flow of DMC was introduced as a spacer using a Tjunction. When the second DMC flow rate was relatively low, the generation of droplets upstream was not disturbed, so that droplets were uniform (Fig. 8b). However, the coalescence at the outlet persisted. Thus, high second DMC flow rates were applied to sufficiently increase the distance between droplets. Nevertheless, this quickly disturbed the generation of droplets upstream, as indicated by heterogeneities in droplet size and frequency (Fig. 8c). Using surfactant would prevent droplet coalescence.

To summarize (Table 1), authors mixed highly concentrated solutions of $\mathrm{Na}$-alginate and water-soluble cross-linkers before droplet generation to make them gelate. However, droplet generation was hindered by rapid gelation and microparticles were difficult to obtain. To delay gelation, less concentrated solutions of $\mathrm{Na}$ alginate and water-soluble cross-linkers were mixed before droplet generation, in the microfluidic device or offline. Then, concentrations were increased after droplet generation by diffusion of water from the droplets to the continuous fluid, due to their partial miscibility with water. Hence, gelation proceeded slowly with droplet shrinkage. However, mixing cross-linkers with $\mathrm{Na}$ alginate before droplet generation led to heterogeneities in droplet size and frequency.

Mixing cross-linkers after droplet generation To delay gelation, water-soluble cross-linkers need to be mixed with $\mathrm{Na}$-alginate only after droplet generation. Studies doing so, and which also use $\mathrm{BaCl}_{2}$ and $\mathrm{CaCl}_{2}$ as cross-linkers, are summarized in Table 2.

$\mathrm{Xu}$ et al. prevented rapid gelation by delaying the direct contact between Na-alginate and calcium cations [54]. In a first cross-junction, two face-to-face channels were used to introduce $\mathrm{CaCl}_{2}(2 \mathrm{wt} \%)$ and $\mathrm{Na}$-alginate ( $2 \mathrm{wt} \%$ ) solutions (Fig. 9a) perpendicularly to a flow of water. Thus, after the first cross-junction, a flow of water (acting as a buffer) separates the flows of $\mathrm{Na}$-alginate and $\mathrm{CaCl}_{2}$. Then octyl alcohol oil (no mention of surfactant) was injected at a second cross-junction. Droplets of $\mathrm{Na}$-alginate $/ \mathrm{CaCl}_{2}$ were generated by flow-focusing. In the "synthesizing channel" (Fig. 9a), within each droplet,

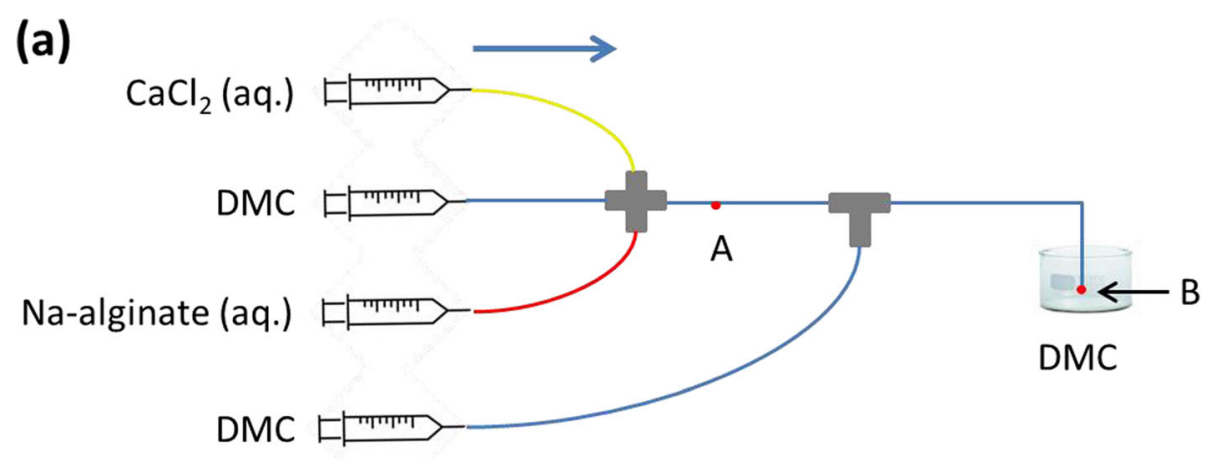

(b)

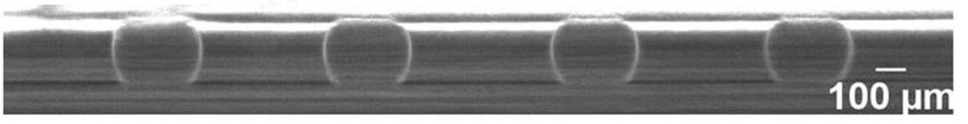

(c)

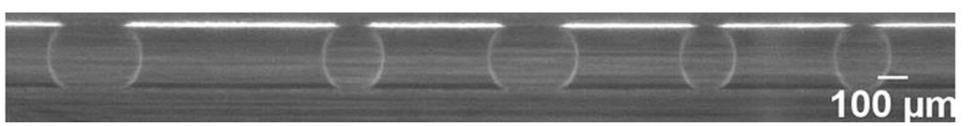

Fig. 8 a Schematic diagram of the generation of Ca-alginate droplets in DMC using a cross-junction. The T-junction served to introduce DMC as a spacer to increase the distance between droplets. The device is composed of polyether ether ketone (PEEK) junctions and Teflon-like tubing (IDEX Health and Science). Micrograph of droplets observed at point A when $\mathbf{b}$ droplet generation was not disturbed by introducing the spacer and $\mathbf{c}$ when it was disturbed 
Table 2 Internal gelation with water-soluble cross-linkers: mixing cross-linkers with Na-alginate after droplet generation

\begin{tabular}{|c|c|c|c|c|}
\hline Reference & & Xu et al., 2008 [54] & Liu et al., 2006 [28] & Trivedi et al., 2010 [47] \\
\hline \multirow[t]{5}{*}{ Droplet generation } & $\begin{array}{l}\text { Concentration of } \mathrm{Na}- \\
\text { alginate }\end{array}$ & $2 \mathrm{wt} \%$ & $2 w t \%$ & $1 \mathrm{wt} \%$ \\
\hline & Continuous fluid & octyl alcohol oil & soybean oil & silicone oil \\
\hline & Use of surfactant & Not mentioned & NO & NO \\
\hline & Geometry & Flow-focusing & Flow-focusing & Flow-focusing \\
\hline & Microfluidic material & PMMA chip & PDMS chip & $\begin{array}{l}\text { Fluoropolymer tubing } \\
\text { and junctions }\end{array}$ \\
\hline \multirow{3}{*}{$\begin{array}{l}\text { Internal gelation by mixing } \\
\text { Na-alginate and water-soluble } \\
\text { cross-linker }\end{array}$} & Cross-linkers & $\mathrm{CaCl}_{2}(2 \mathrm{wt} \%)$ & $\mathrm{CaCl}_{2}(2 \mathrm{wt} \%)$ & $\mathrm{BaCl}_{2}(50 \mathrm{mM})$ \\
\hline & Geometry & Cross-flowing & Expansion chamber & Cross-flowing \\
\hline & Mixing & $\begin{array}{l}\text { Coalescence of } \\
\text { flows }\end{array}$ & $\begin{array}{l}\text { Coalescence of } \\
\text { droplets }\end{array}$ & $\begin{array}{l}\text { Coalescence of droplets with } \\
\text { flow }\end{array}$ \\
\hline
\end{tabular}

mixing $\mathrm{Na}$-alginate and $\mathrm{CaCl}_{2}$ induced internal gelation. In this way droplets were transformed into $\mathrm{Ca}$-alginate hydrogel microparticles (Fig. 9b). For this strategy, the size of Ca-alginate hydrogel microparticles is entirely dependent on the experimental conditions, such as flow rates of fluids and channel size. Manipulation of microparticles is difficult if their diameter is smaller than $10 \mu \mathrm{m}$.

Another strategy to delay gelation was carried out by Liu et al. [28] involving coalescence of Na-alginate droplets with $\mathrm{CaCl}_{2}$ droplets generated separately. First, on a microfluidic chip (Fig. 10a), Na-alginate (2 wt\%) droplets (Fig. 10b) and $\mathrm{CaCl}_{2}$ (2 wt\%) droplets (Fig. 10c) were generated in soybean oil without surfactant by flowfocusing using two independent cross-junctions. Then droplets converged via a T-junction (Fig. 10d) followed by two successive circular expansion chambers (Fig. 10d, e). Thus, droplets could collide either at the T-junction or in circular chambers. Within the coalesced droplets, $\mathrm{Na}$-alginate was crosslinked by calcium cations forming Ca-alginate hydrogel microparticles. With different flow rates and channel geometries, various shapes and sizes of microparticles could be produced (Fig. 10f). Nevertheless, the design of circular expansion chambers gives rise to local changes in flow velocity. Droplet circulation can be disturbed, thereby affecting homogeneity in droplet shape, size and frequency.

Droplets could also be coalesced by exploiting physicochemical parameters between the continuous fluid and the dispersed fluid. In the work of Trivedi et al., droplets of $\mathrm{Na}$-alginate $(1 \mathrm{wt} \%)$ containing cells were generated upstream in a highly viscous silicone oil (10 centistoke) by flow-focusing without surfactant $[47,48]$. An aqueous solution of $\mathrm{BaCl}_{2}(50 \mathrm{mM})$ was injected downstream by a $\mathrm{T}$-junction. With the help of dye, observations at the $\mathrm{T}$-junction indicated that $\mathrm{BaCl}_{2}$ fluid
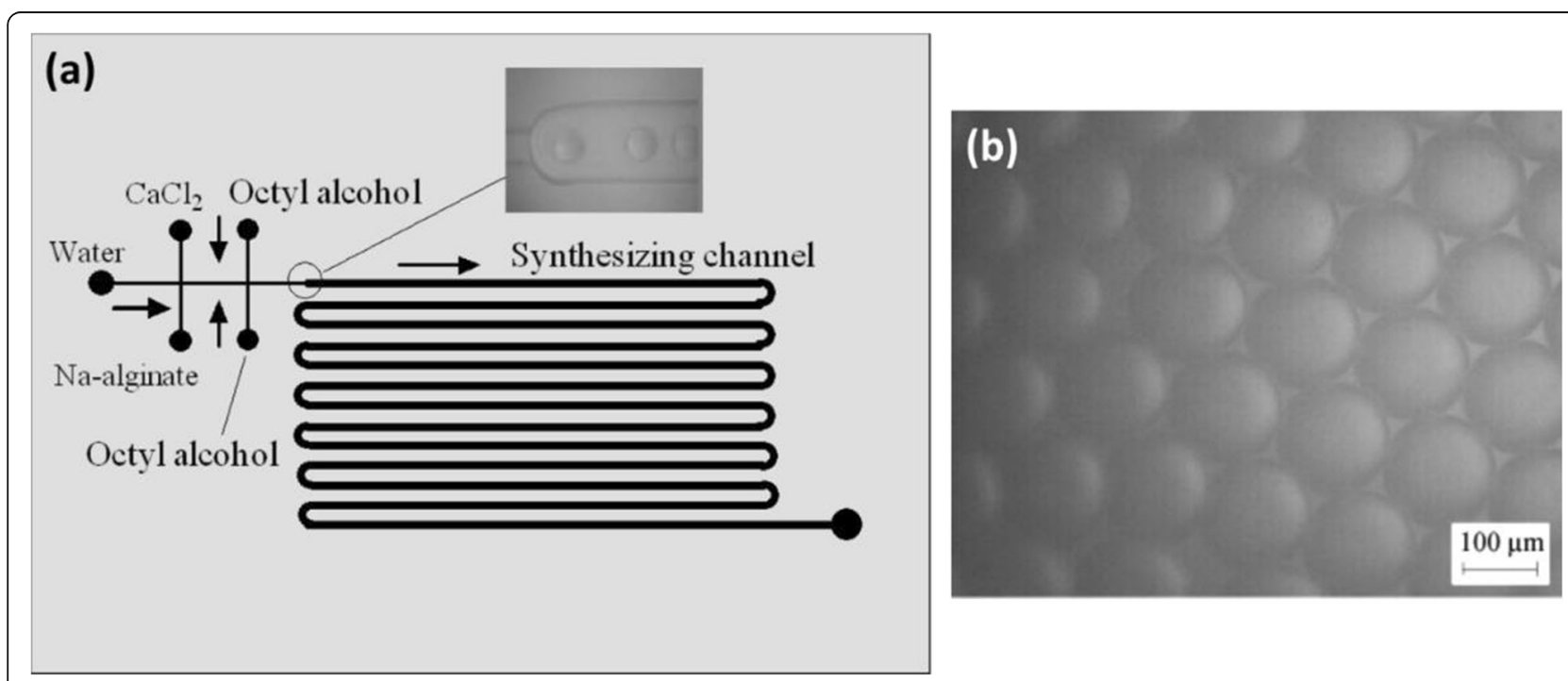

Fig. 9 a Schematic diagram of Ca-alginate hydrogel microparticles prepared in a PMMA based microfluidic device. b Micrographs of Ca-alginate hydrogel microparticles. Figure reprinted with permission from Reference [54] 


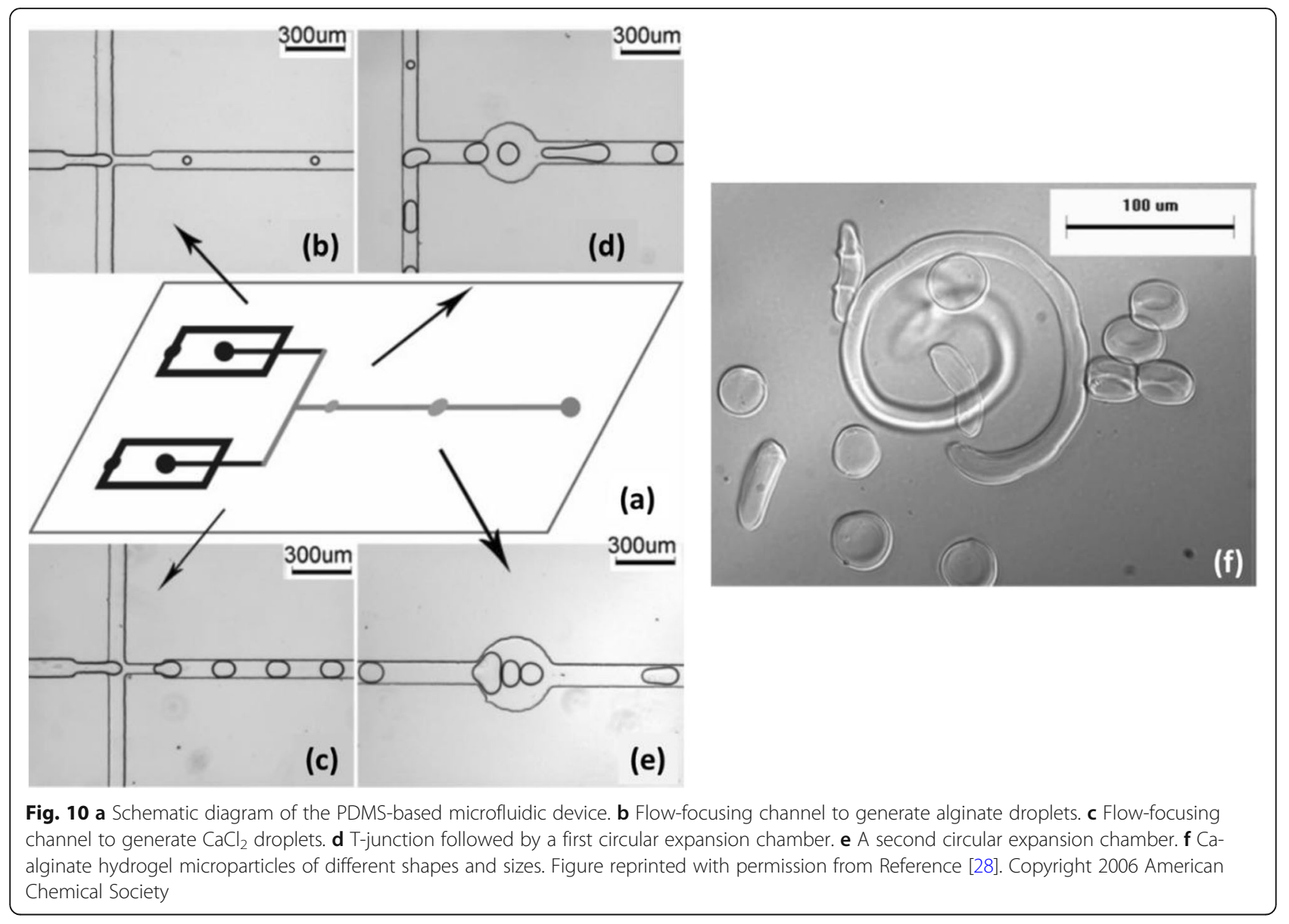

merged spontaneously with $\mathrm{Na}$-alginate/cells droplets, instead of forming independent $\mathrm{BaCl}_{2}$ droplets. However, this strategy lacks flexibility. The expected coalescence happens only when appropriate solvents are used. For instance, when using low-viscosity and lowinterfacial energy $\gamma_{\mathrm{CD}}$ soybean oil, independent droplets of $\mathrm{BaCl}_{2}$ were observed. They coalesced downstream with $\mathrm{Na}$-alginate/cells droplets. This implied that successful coalescence of droplets could only take place with appropriate interfacial energy and viscosity [48].

\section{Water-insoluble or weakly soluble cross-linkers}

To delay gelation, Na-alginate can be mixed with waterinsoluble or weakly soluble cross-linkers, in water. This will not lead to instant gelation since there are no available cations in water. In the case of cross-linkers which are $\mathrm{pH}$-sensitive, such as calcium carbonate $\left(\mathrm{CaCO}_{3}\right)$ and calcium-ethylenediaminetetraacetic acid (Ca-EDTA) complex, an acid is used in the continuous fluid to release the cations from inert cross-linkers. Therefore, gelation by the available cations happens after droplet generation. These strategies are summarized in Table 3.

In the work of Zhang et al. [61], fine particles of $\mathrm{CaCO}_{3}(0.1 \mathrm{wt} \%)$ were dispersed in an aqueous solution of Na-alginate (2wt\%). Soybean oil with a surfactant (Span 80, $3 \mathrm{wt} \%$ ) and containing acetic acid (5 wt\%) was used as the continuous fluid (Fig. 11a). Droplets of Naalginate $/ \mathrm{CaCO}_{3}$ were generated by flow-focusing in soybean oil/acetic acid (Fig. 11b). Droplets pH decreased because of the acetic acid in the oil. As a result, calcium cations were released from $\mathrm{CaCO}_{3}$, causing internal gelation of the alginate. Finally, Ca-alginate hydrogel microparticles were collected in oil (Fig. 11c). However, when collected on a substrate, they had a "pancake" shape and were soluble in aqueous solution owing to insufficient gelation. No improvement was observed from increasing the concentration of acetic acid or that of $\mathrm{CaCO}_{3}$. Moreover, a higher concentration of $\mathrm{CaCO}_{3}$ particles would give rise to their aggregation in the channel [61]. The mechanical properties of the microparticles could not therefore be improved.

The same principle was also applied by Akbari and Pirbodaghi to prepare cell-encapsulating microparticles (Fig. 12) [3]. At a first T-junction, a fluid of Na-alginate (1.5 wt\%) containing cells flowed into the middle channel (Fig. 12a), while the Na-alginate fluid (1.5 wt\%) containing $\mathrm{CaCO}_{3}$ nanoparticles $(35 \mathrm{mM})$ was introduced by two side channels (Fig. 12b). This geometry was used to 
Table 3 Internal gelation with water-insoluble or weakly soluble cross-linkers which are $\mathrm{pH}$ sensitive

\begin{tabular}{|c|c|c|c|c|c|}
\hline References & & $\begin{array}{l}\text { Zhang et al., } 2007 \\
\text { [61] }\end{array}$ & $\begin{array}{l}\text { Akbari and Pirbodaghi, } \\
2014 \text { [3] }\end{array}$ & Yu et al., 2019 [56] & $\begin{array}{l}\text { Utech et al., } 2015 \\
\text { [49] }\end{array}$ \\
\hline \multirow[t]{5}{*}{ Droplet generation } & $\begin{array}{l}\text { Concentration of } \\
\mathrm{Na} \text {-alginate }\end{array}$ & $2 w t \%$ & 1,5 wt $\%$ & $2 \mathrm{w} / \mathrm{v} \%$ & $2 w t \%$ \\
\hline & Continuous fluid & Soybean oil & Fluorocarbon oil & Mineral oil & $\begin{array}{l}\text { Fluorinated carbon } \\
\text { oil }\end{array}$ \\
\hline & Use of surfactant & Span 80 & Fluorinated surfactant & Span 80 & $\begin{array}{l}\text { Biocompatible } \\
\text { surfactant }\end{array}$ \\
\hline & Geometry & Flow-focusing & Flow-focusing & Flow-focusing & Flow-focusing \\
\hline & $\begin{array}{l}\text { Microfluidic } \\
\text { material }\end{array}$ & PDMS chip & PDMS chip & PDMS chip & PDMS chip \\
\hline \multirow{3}{*}{$\begin{array}{l}\text { Internal gelation by mixing } \\
\text { Na-alginate and water-insoluble } \\
\text { or weakly soluble cross-linkers }\end{array}$} & Cross-linkers & $\mathrm{CaCO}_{3}(0,1 \mathrm{wt} \%)$ & $\mathrm{CaCO}_{3}(35 \mathrm{mM})$ & $\mathrm{CaCO}_{3}(200 \mathrm{mM})$ & Ca-EDTA (50 mM) \\
\hline & Mixing & $\begin{array}{l}\text { Off-line, before } \\
\text { droplet generation }\end{array}$ & $\begin{array}{l}\text { Before droplet } \\
\text { generation }\end{array}$ & $\begin{array}{l}\text { Off-line, before } \\
\text { droplet generation }\end{array}$ & $\begin{array}{l}\text { Off-line, before } \\
\text { droplet generation }\end{array}$ \\
\hline & $\begin{array}{l}\text { Gelation by acid } \\
\text { addition }\end{array}$ & In continuous fluid & In continuous fluid & In collecting fluid & In continuous fluid \\
\hline
\end{tabular}

create a coaxial stream while avoiding direct mechanical contact between cells and the potentially damaging $\mathrm{CaCO}_{3}$ particles. At a second T-junction, fluorocarbon oil with surfactant (fluorinated surfactant, $1 \mathrm{wt} \%$ ) was injected. Droplets of $\mathrm{Na}$-alginate/cells $/ \mathrm{CaCO}_{3}$ were then generated by flow-focusing. After droplet collection, acetic acid ( 0.1 vol\%) dissolved in oil was added to release calcium cations within droplets, causing gelation of alginate. Droplets were thus transformed into $\mathrm{Ca}$ alginate hydrogel microparticles, some with cells encapsulated (Fig. 12c). However, the mixture of $\mathrm{CaCO}_{3}$ and Na-alginate was not homogeneous, which can be seen from Fig. 12b. Thus, the varying amounts of $\mathrm{CaCO}_{3}$ influenced the degree of gelation in each droplet, yielding Ca-alginate hydrogel microparticles with different mechanical properties. This issue is not discussed by Akbari and Pirbodaghi [3]. Furthermore, not all microparticles encapsulated cells, for reasons not explored in the article. Sorting is therefore required after the preparation of microparticles, which complicates the procedure.

Combining the strategy of Zhang et al. and Akbari and Pirbodaghi to conduct gelation both in the microfluidic device and in the collection bath, Yu et al. [56] produced Ca-alginate hydrogel microparticles for protein

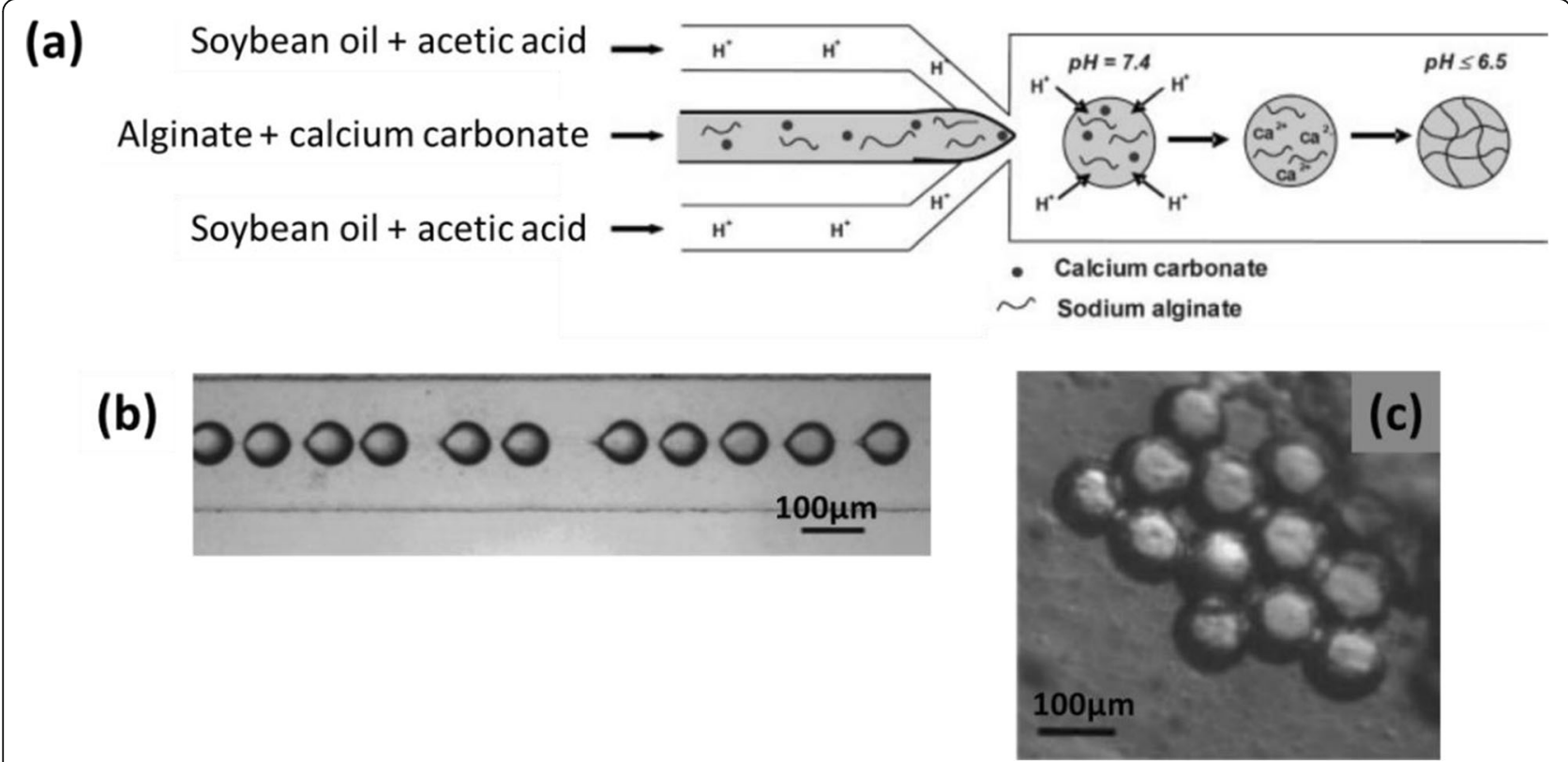

Fig. 11 a Schematic diagram of the preparation of Ca-alginate hydrogel microparticles by using $\mathrm{CaCO}_{3}$ to perform internal gelation of alginate in a PDMS-based microfluidic device. Micrograph of $\mathbf{b}$ droplets generated in the channel and $\mathbf{c}$ Ca-alginate hydrogel microparticles collected in oil. Figure reprinted with permission from Reference [61] 


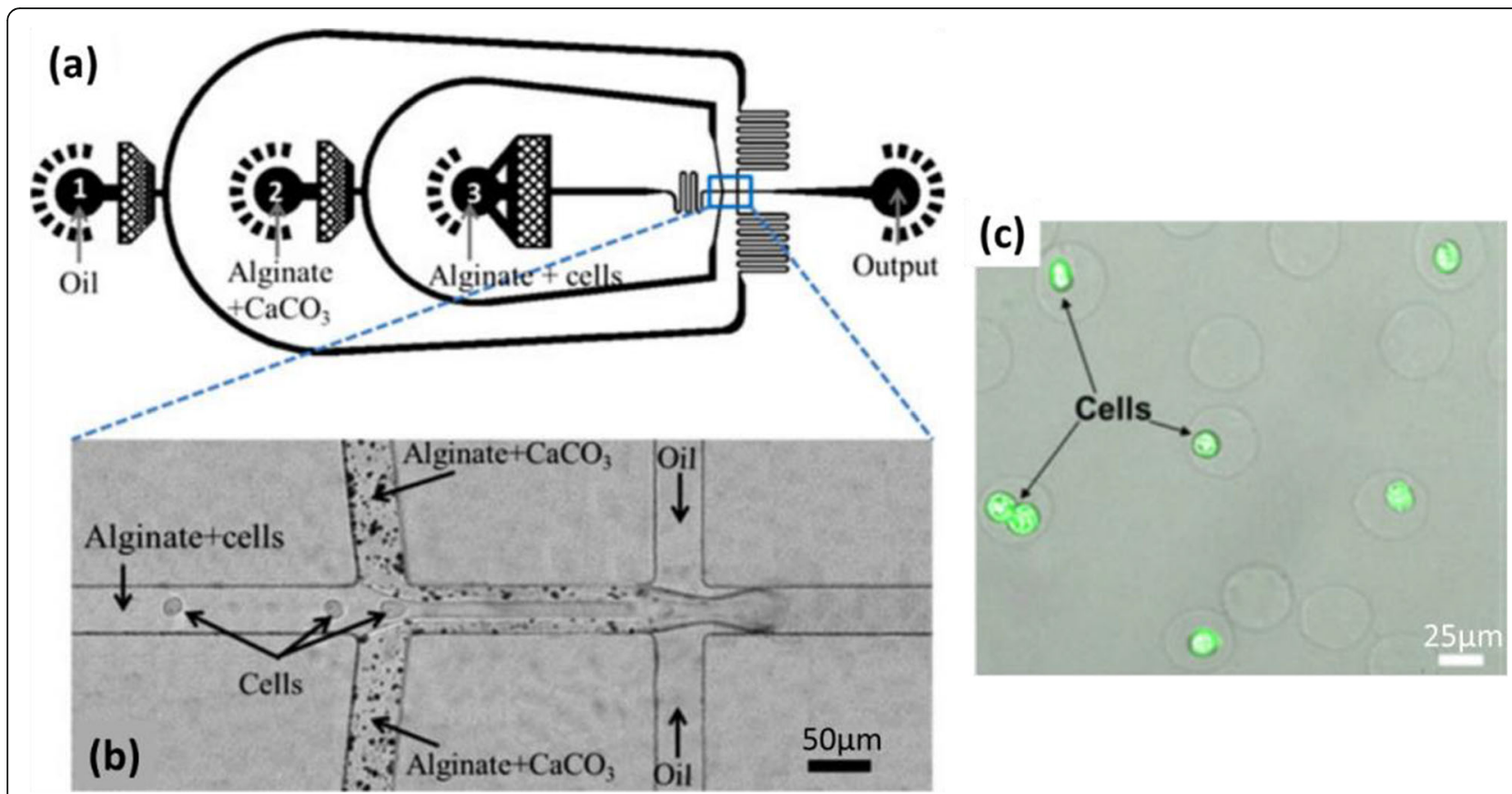

Fig. 12 a Schematic diagram of a PDMS-based microfluidic device for the generation of droplets. $\mathbf{b}$ Micrograph of the two cross-junctions in the microfluidic device. c Confocal microscopic image of Ca-alginate hydrogel microparticles, some with cells encapsulated (Green fluorescence represents live cells stained by calcein AM). Figure reprinted with permission from Reference [3]

encapsulation. First, from inlet 4 (Fig. 13a), an aqueous solution of antigen or protein was injected. It co-flowed with another aqueous solution of alginate $(2 \mathrm{w} / \mathrm{v} \%)$ mixed with $\mathrm{CaCO}_{3}$ particles $(200 \mathrm{mM})$ and injected from inlet 3. Mineral oil with Span 80 added was injected from inlet 2 as a continuous fluid. In the flow-focusing channel, droplets containing alginate, $\mathrm{CaCO}_{3}$ and protein were formed. From inlet 1, another continuous fluid, mineral oil containing Span 80 and acetate acid, was introduced. When the acetate acid diffused into droplets, calcium cations were released. The alginate was then crosslinked, leading to preliminary gelation. The droplets were collected in an aqueous solution of $\mathrm{CaCl}_{2}(0.27 \mathrm{M})$ to enhance gelation. In the end, spherical hydrogel microparticles were formed, with protein encapsulated (Fig. 13b-c). According to the authors, the preliminary gelation in the microchannel prevented the deformation that occurs when droplets are collected directly in an aqueous solution of $\mathrm{CaCl}_{2}$. As mentioned above, however, since $\mathrm{CaCO}_{3}$ is not soluble in water, a high concentration of $\mathrm{CaCO}_{3}$ will clog the microchannel. Thus, the scope for preliminary gelation is limited. Moreover, it takes time (in this case, overnight) to obtain a mixture where $\mathrm{CaCO}_{3}$ particles are well dispersed.

In order to obtain a homogeneous internal structure of hydrogel microparticles, Utech et al. used a slightly water-soluble calcium-ethylenediaminetetraacetic acid (Ca-EDTA) complex as the cross-linker [49]. An aqueous solution of $\mathrm{Na}$-alginate (2 $\mathrm{wt} \%)$ mixed with $\mathrm{Ca}$ -
EDTA $(50 \mathrm{mM})$ was first prepared. This homogeneous mixture was used as the dispersed fluid for the microfluidic system. The continuous fluid was a fluorinated carbon oil with a biocompatible surfactant (1 wt\%) containing acetic acid (0.05 vol\%). Droplets of Na-alginate/ Ca-EDTA were generated in oil/acetic acid by flowfocusing (Fig. 14a). Due to the use of acetic acid, calcium cations were released from Ca-EDTA in each droplet (Fig. 14b), causing internal gelation of the alginate. The Ca-alginate hydrogel microparticles formed (Fig. 14c) had a homogeneous internal structure and were stable in an aqueous medium without dissolution. It should be noted that, the solubility of Ca-EDTA in water being low $\left(0.26 \mathrm{M}\right.$ at $\left.20^{\circ} \mathrm{C}\right)$, the concentration of Ca-EDTA in the Na-alginate solution was limited in order to keep the solution homogeneous. Thus, this strategy is not appropriate when microparticles need to be highly crosslinked. Furthermore, care should be taken with Ca-EDTA, as EDTA is used to dissolve alginate hydrogel microparticles in the literature $[29,56]$.

In conclusion, internal gelation of alginate can be realized by using cross-linkers that are soluble or insoluble/ slightly soluble in water. When water-soluble crosslinkers are used, the instant gelation disturbs droplet generation. The problem can be solved by using partially miscible fluids with limited mixing prior to droplet generation, and/or by using extremely diluted solutions and surfactant (Table 1). Mixing cross-linkers and $\mathrm{Na}$ alginate after droplet generation involves merging 

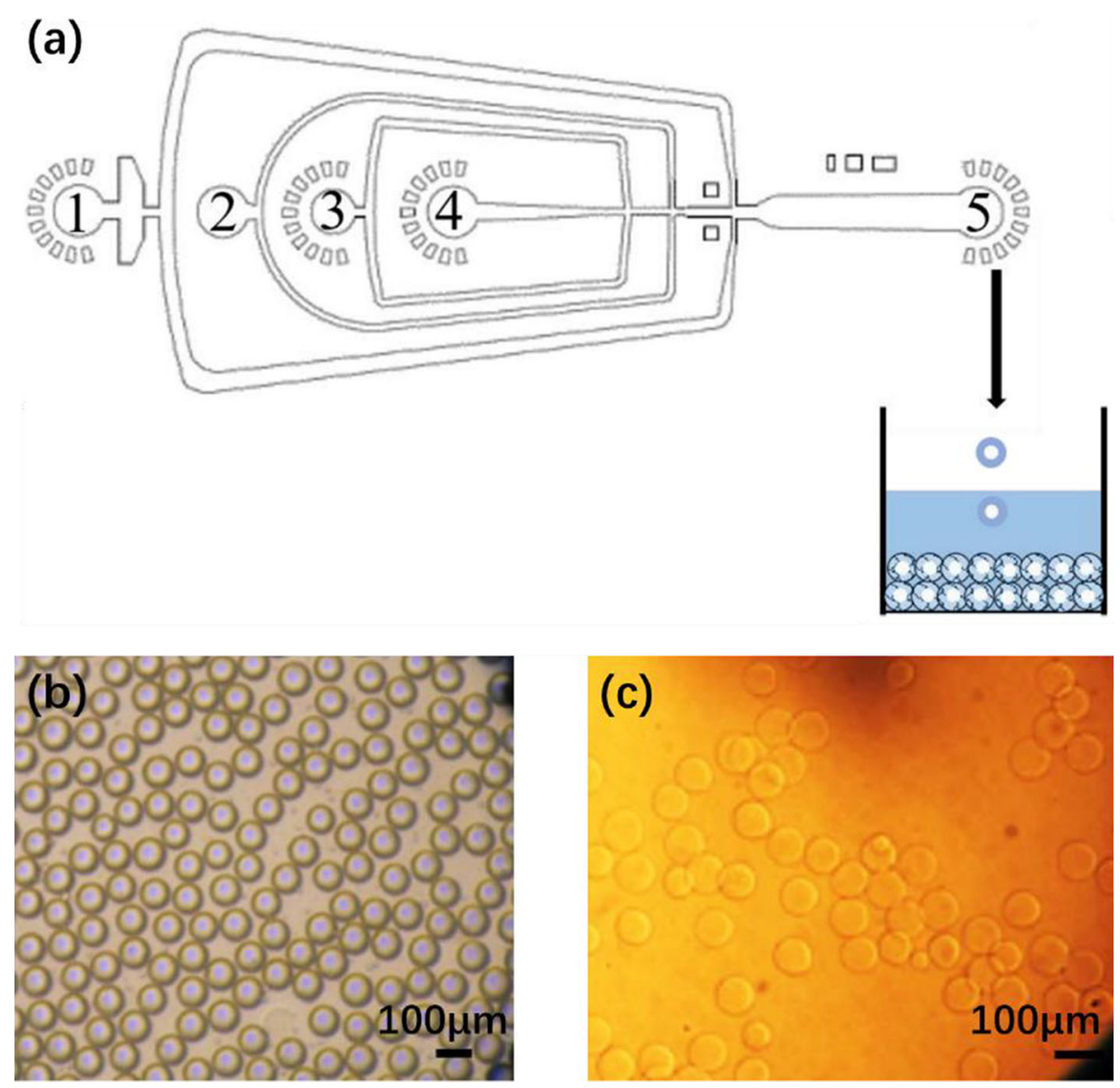

Fig. 13 a Schematic diagram of a PDMS-based microfluidic device for the preparation of antigen-core alginate-shell microparticles. Inlet 1: Mineral oil with 3 wt $\%$ Span 80 and 0.2 vol\% acetic acid; Inlet 2: Mineral oil with 3 wt\% Span 80; Inlet 3: 2 w/v\% alginate solution containing 200 mM CaCO ; Inlet 4: an antigen or protein aqueous solution. Micrographs of Ca-alginate hydrogel microparticles in $\mathbf{b}$ oil and $\mathbf{c}$ water. Figure reprinted with permission from Reference [56]

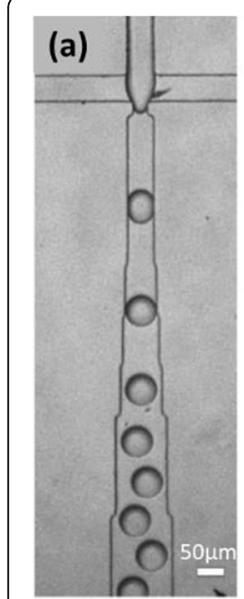

(b)
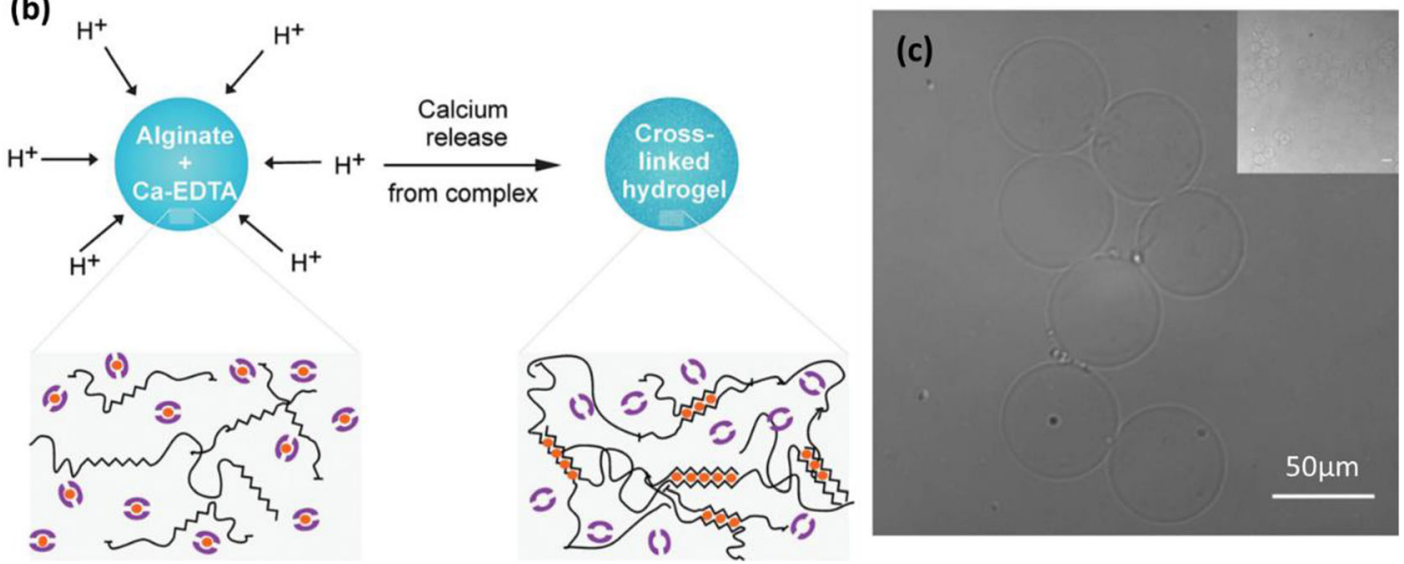

Fig. 14 a Micrograph of the T-junction in a microfluidic device, where droplets of Na-alginate/Ca-EDTA were generated in oil/acetic acid. $\mathbf{b}$ Schematic illustration of the crosslinking process in each droplet. c Micrograph of Ca-alginate hydrogel microparticles in an aqueous medium. Figure reprinted with permission from Reference [49] 
droplets or flows of Na-alginate and water-soluble crosslinkers (Table 2). The resulting droplets are dependent on physicochemical properties like viscosity and interfacial energy. If water-insoluble/slightly soluble crosslinkers are used, they are mixed with alginate before droplet generation. For $\mathrm{pH}$-sensitive cross-linkers, acid is then needed to release cations, after which internal gelation takes place (Table 3).

A homogeneous microparticle internal structure can be achieved by choosing appropriate cross-linkers. However, because of low solubility in water, it is important to limit the concentration of cross-linkers to avoid precipitates in the channel.

\section{External gelation}

In external gelation, cross-linkers come from outside the alginate droplets and are diffused into the alginate droplets or the microparticles formed, inducing crosslinking. Unlike internal gelation, in which cross-linkers are always introduced "on-chip" (in the microfluidic device), in external gelation, cross-linkers can be introduced both "on-chip" and/or "off-chip" (outside the microfluidic device).

\section{On-chip introduction of cross-linkers}

For external gelation, several authors introduced crosslinkers "on-chip". They used calcium acetate (Ca $\left.\left(\mathrm{CH}_{3} \mathrm{COO}\right)_{2}\right)$ or $\mathrm{CaCl}_{2}$ as cross-linkers, as summarized in Table 4.

Cross-linkers can be contained in the continuous fluid, as described in Zhang et al. [61] $\mathrm{Ca}\left(\mathrm{CH}_{3} \mathrm{COO}\right)_{2}(2 \mathrm{wt} \%)$ was dissolved in soybean oil, the continuous fluid. In the microfluidic device detailed previously [61], Na-alginate (2 wt\%) droplets were generated by flow-focusing (Fig. 15a) in oil/Ca $\left(\mathrm{CH}_{3} \mathrm{COO}\right)_{2}$, with surfactant (Span 80,3 wt\%). $\mathrm{Ca}\left(\mathrm{CH}_{3} \mathrm{COO}\right)_{2}$ diffused and dissolved in $\mathrm{Na}-$ alginate droplets along the channel (Fig. 15b), causing external gelation on-chip. Finally, Ca-alginate hydrogel microparticles were collected in oil (Fig. 15c). They showed better stability in an aqueous medium and had a higher Young's modulus compared with those produced by internal gelation (III.1.2.). Consequently, stronger gelation was achieved by external gelation. However, increasing the concentration of $\mathrm{Ca}$ $\left(\mathrm{CH}_{3} \mathrm{COO}\right)_{2}$ in soybean oil caused clogging in the microchannel [61]. Thus, it is difficult to vary the rate of gelation of microparticles.

One way to limit channel clogging is to make the cross-linkers diffuse slowly in Na-alginate droplets. Thus, Liu et al. used emulsion fluids to introduce cross-linker s[29]. A glass-based microfluidic device was used, with channels modified so as to be hydrophobic. Droplets of Na-alginate (3wt\%) were first generated in corn oil at the first flow-focusing channel (Fig. 16a). The emulsion of $\mathrm{CaCl}_{2}$, containing $\mathrm{CaCl}_{2}$ droplets in corn oil (with surfactant SY-Glyster CRS-75), was injected downstream of the crossjunction. The contact between $\mathrm{CaCl}_{2}$ and $\mathrm{Na}$-alginate droplets caused ionic crosslinking, leading to gelation. Ca-alginate hydrogel microparticles were obtained. However, it was found that the microparticles could easily be deformed (Fig. 16b-A, b-C) by several

Table 4 External gelation with on-chip introduction of cross-linkers

\begin{tabular}{|c|c|c|c|c|c|}
\hline Reference & & $\begin{array}{l}\text { Zhang } \\
\text { et al., } 2007 \\
{[61]}\end{array}$ & $\begin{array}{l}\text { Liu et al., } 2019 \\
\text { [29] }\end{array}$ & $\begin{array}{l}\text { Sugaya et al., } \\
2011 \text { [44] }\end{array}$ & $\begin{array}{l}\text { Pittermannová et al., } 2016 \\
\text { [34] }\end{array}$ \\
\hline \multirow[t]{5}{*}{ Droplet generation } & $\begin{array}{l}\text { Concentration } \\
\text { of Na-alginate }\end{array}$ & $2 \mathrm{wt} \%$ & 3 wt $\%$ & $0.025-0.15$ wt $\%$ & $1 \mathrm{w} / \mathrm{v} \%$ \\
\hline & $\begin{array}{l}\text { Continuous } \\
\text { fluid }\end{array}$ & Soybean oil & Corn oil & Methyl acetate & 1-undecanol \\
\hline & $\begin{array}{l}\text { Use of } \\
\text { surfactant }\end{array}$ & Span 80 & $\begin{array}{l}\text { SY-Glyster } \\
\text { CRS-75 }\end{array}$ & Not mentioned & Abil Em 90 \\
\hline & Geometry & $\begin{array}{l}\text { Flow- } \\
\text { focusing }\end{array}$ & Flow-focusing & Flow-focusing & Flow-focusing \\
\hline & $\begin{array}{l}\text { Microfluidic } \\
\text { material }\end{array}$ & PDMS chip & Glass chip & PDMS chip & PDMS chip \\
\hline \multirow[t]{3}{*}{$\begin{array}{l}\text { External gelation by introducing } \mathrm{Na} \text { - } \\
\text { alginate and cross-linkers on chip before } \\
\text { collection }\end{array}$} & Cross-linkers & $\begin{array}{l}\mathrm{Ca} \\
\left(\mathrm{CH}_{3} \mathrm{COO}\right)_{2} \\
(2 \text { wt\%) } \\
\text { in the } \\
\text { continuous } \\
\text { fluid }\end{array}$ & $\begin{array}{l}\text { Emulsion of } \mathrm{CaCl}_{2} \\
\text { in the continuous } \\
\text { fluid }\end{array}$ & $\begin{array}{l}\mathrm{CaCl}_{2}(1 \mathrm{M}) \text { in } \\
\text { the dispersed } \\
\text { fluid }\end{array}$ & $\begin{array}{l}\text { Emulsion of } \mathrm{CaCl}_{2}(2 \mathrm{wt} \%) \\
\text { droplets in the continuous } \\
\text { fluid }\end{array}$ \\
\hline & Geometry & - & Flow-focusing & Cross-flowing & Flow-focusing \\
\hline & Mixing & $\begin{array}{l}\text { During } \\
\text { droplet } \\
\text { generation }\end{array}$ & $\begin{array}{l}\text { After droplet } \\
\text { generation }\end{array}$ & $\begin{array}{l}\text { After droplet } \\
\text { generation }\end{array}$ & After droplet generation \\
\hline
\end{tabular}



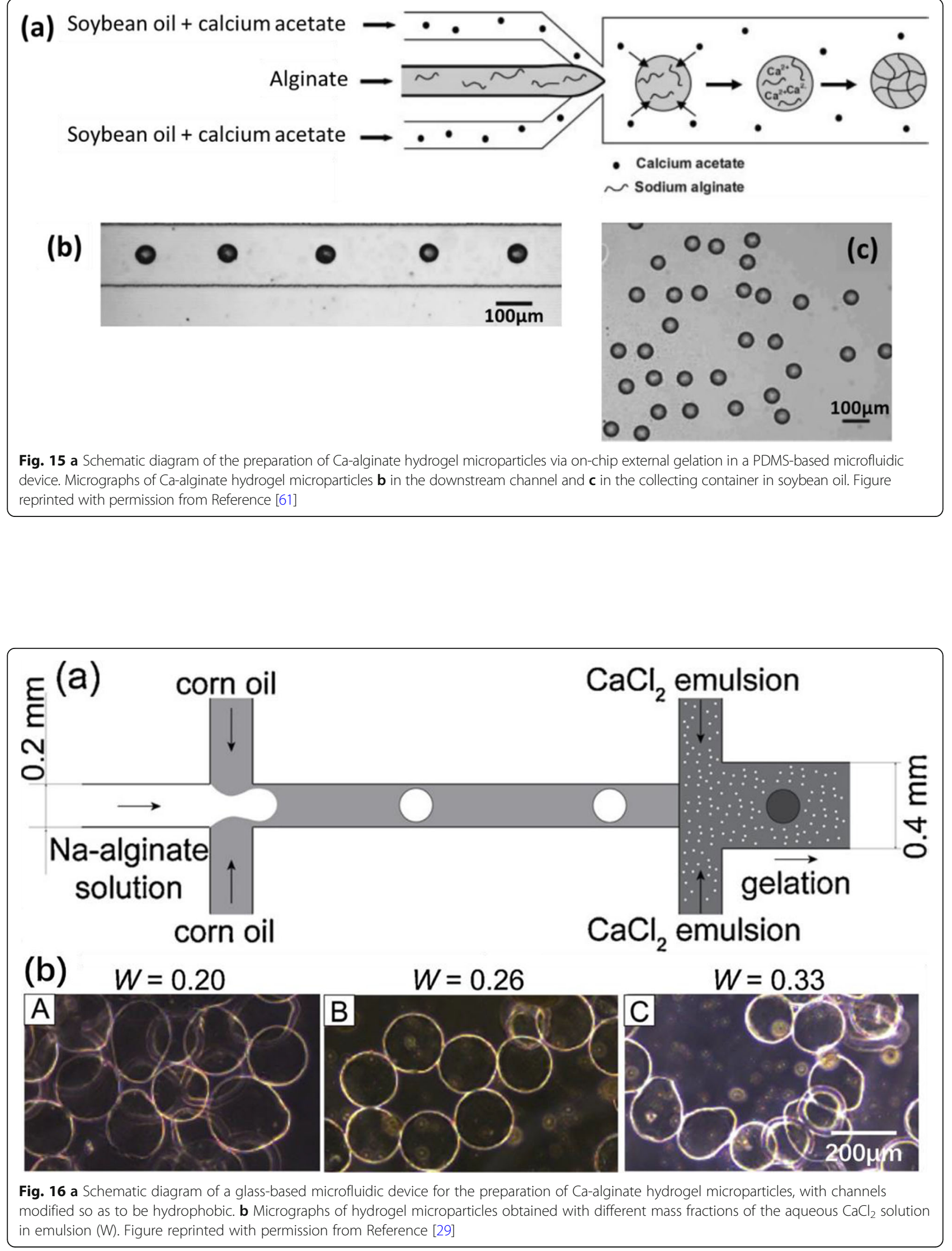
parameters, such as the mass fraction of the aqueous $\mathrm{CaCl}_{2}$ solution in emulsion (W). Deformation occurred when the value of W was too high or too low, so that an optimal value of W was required for homogeneous spherical microparticles (Fig. 16b-B). The morphology and homogeneity of microparticles also varied with flow rates and surfactant concentrations. Lacking flexibility, this strategy is thus not appropriate for producing spherical hydrogel microparticles. Moreover, generating small particles requires reducing the channel size, involving a risk of droplet coalescence before gelation in $\mathrm{CaCl}_{2}$ emulsion.

To avoid reducing the channel size, partially miscible fluids can be used as the dispersed and continuous fluids. Sugaya et al. used methyl acetate as the continuous fluid [44]. Na-alginate $(0.025-0.15 \mathrm{wt} \%)$ droplets were generated in methyl acetate (no mention of surfactant usage) by flow-focusing. In the following channel, because of the solubility of water in methyl acetate $(8 \mathrm{wt} \%)$, water dissolved gradually from the droplets into methyl acetate. Thus, the droplets shrank and became more concentrated downstream. $\mathrm{CaCl}_{2}$ solution (1 M) was then injected by side channels and flowed with the droplets by co-flow. Calcium cations diffused into the droplets, inducing on-chip external gelation of alginate. Finally, spherical Ca-alginate hydrogel microparticles with a diameter of less than $20 \mu \mathrm{m}$ were obtained. In this strategy, after $\mathrm{CaCl}_{2}$ fluids were introduced, two competing processes occurred simultaneously in each droplet: gelation and shrinkage of droplets. The competition between gelation and shrinkage is not discussed in this article. However, the results indicate that extremely small droplets tend to approach the channel wall after shrinkage. With the $\mathrm{CaCl}_{2}$ fluid,

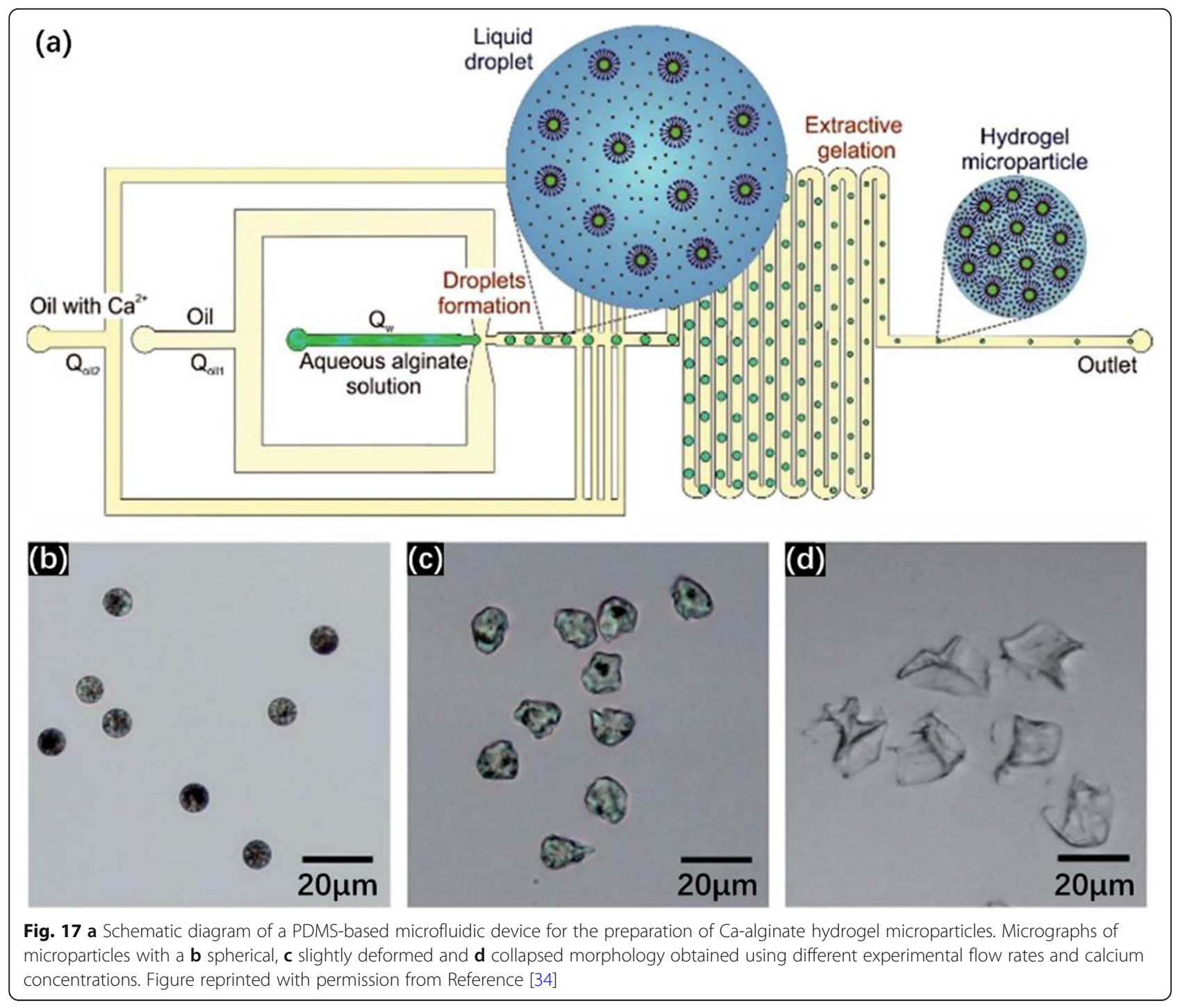


after gelation, Ca-alginate hydrogel microparticles adhere to the channel wall.

Adhesion to the channel and coalescence of microparticles can be avoided thanks to progressive addition of the cross-linker. Pittermannová et al. used as continuous fluid 1-undecanol, whose water-solubility is $2.7 \mathrm{vol} \%$ [34]. The experiment was carried out in a PDMS-based microfluidic device (Fig. 17a). An aqueous alginate solution (1 wt\%) was first injected. After 1-undecanol (with 5 wt\% surfactant Abil Em 90), shown as "oil" in Fig. 17a, was injected into the flow-focusing channel, droplets of alginate were formed. $\mathrm{CaCl}_{2}(2 \mathrm{wt} \%)$ was dispersed in another fluid, 1-undecanol with $5 \mathrm{wt} \%$ surfactant Abil Em 90, yielding an emulsion. This emulsion was injected after droplet generation, through successive channels (Fig. 17a). Hence, the droplets were increasingly separated from each other, avoiding coalescence. Moreover, they were surrounded by more and more $\mathrm{CaCl}_{2}$, increasing gelation, and by more and more 1-undecanol, increasing diffusion of water. Thus, gelation and shrinkage of droplets occurred gradually and simultaneously. According to the authors, this procedure avoids the droplet generation instability caused by pre-gelation. However, spherical hydrogel microparticles (Fig. 17b) were only obtained using certain flow rates and calcium concentrations. Otherwise, the microparticles were slightly deformed (Fig. 17c) or collapsed (Fig. 17d), which was explained using a core-shell model [34]. Unfortunately, this explanation does not take into account the change in alginate concentration in the droplets due to water extraction, a factor which is bound to impact deformation. Simply prolonging the water extraction process before introducing cross-linkers, as done by Sugaya et al., could avoid deformation [44].

\section{Off-chip introduction of cross-linkers}

Other strategies of external gelation introduce crosslinkers "off-chip", i.e., during droplet collection. Ca $\left(\mathrm{CH}_{3} \mathrm{COO}\right)_{2}$ or $\mathrm{CaCl}_{2}$ are used as cross-linkers and the collection bath procedure depends on the strategy, as summarized in Table 5.

$\mathrm{Hu}$ et al. [20] studied the influence of external gelation conditions on the shape of microparticles. Na-alginate (1.5 wt\%) droplets were first generated in n-decanol with surfactant (Span 80, $5 \mathrm{wt} \%$ ), using concentric glass capillaries in co-flow geometry (Fig. 18A). For off-chip external gelation, droplets were collected in a two-phase gelation bath: the upper phase of $\mathrm{n}$-decanol with surfactant (Span 80, $5 \mathrm{wt} \%$ ) containing $\mathrm{CaCl}_{2}$ (15 wt\%) allowed for pre-gelation of alginate; the bottom phase, an aqueous solution of barium acetate (15 wt\%), strengthened the gelation. Glycerol $(0-70 \mathrm{wt} \%)$ was added to the bottom phase to regulate viscosity. Ca-alginate hydrogel particles of different shapes (Fig. 18B) were obtained by varying gelation conditions such as the interfacial energy $\gamma_{\mathrm{CD}}$, the concentration and type of surfactant, the height $h$ between the end of the capillary and the surface of the gelation bath, and the viscosity of the bottom phase in the gelation bath. The shape of microparticles was shown to depend on forces applied to the surface of droplets when they passed through the interface in the gelation bath. The force from $\gamma_{\mathrm{CD}}$ maintains the spherical form of droplets, while the viscous force causes deformation. The final shape resulted from the overall effect of these two forces [20]. As can be seen in this strategy, droplet collection is accompanied by the consumption of the two different cations. Thus, to obtain a large quantity of microparticles, these cations should be replenished to ensure that each droplet undergoes

Table 5 External gelation with off-chip introduction of cross-linkers

\begin{tabular}{|c|c|c|c|c|c|c|}
\hline \multicolumn{2}{|l|}{ References } & \multicolumn{2}{|c|}{ Hu et al., 2012 [20] } & Zhang et al., 2020 [59] & \multicolumn{2}{|c|}{ Present review } \\
\hline \multirow[t]{5}{*}{ Droplet generation } & Na-alginate & \multicolumn{2}{|c|}{$1.5 \mathrm{wt} \%$} & $0.006-1 \mathrm{wt} \%$ & \multicolumn{2}{|c|}{$0.006-1 \mathrm{wt} \%$} \\
\hline & Continuous fluid & \multicolumn{2}{|c|}{ N-decanol } & $\mathrm{DMC}^{\mathrm{a}}$ & \multicolumn{2}{|c|}{$\mathrm{DMC}^{\mathrm{a}}$} \\
\hline & Use of surfactant & \multicolumn{2}{|c|}{ Span 80} & NO & \multicolumn{2}{|l|}{ NO } \\
\hline & Geometry & \multicolumn{2}{|c|}{ Flow-focusing } & Cross-flowing & \multicolumn{2}{|c|}{ Cross-flowing } \\
\hline & Microfluidic material & \multicolumn{2}{|c|}{ Glass chip } & $\begin{array}{l}\text { Fluoropolymer tubing } \\
\text { and junctions }\end{array}$ & \multicolumn{2}{|c|}{$\begin{array}{l}\text { Fluoropolymer tubing and } \\
\text { junctions }\end{array}$} \\
\hline \multirow{4}{*}{$\begin{array}{l}\text { External gelation by introducing } \\
\text { Na-alginate and cross-linkers } \\
\text { off-chip during collection }\end{array}$} & $\begin{array}{l}\text { Number of phases or } \\
\text { steps }\end{array}$ & \multicolumn{2}{|c|}{2 phases - 1 collection bath } & $\begin{array}{l}1 \text { phase - } 1 \text { collection } \\
\text { bath }\end{array}$ & \multicolumn{2}{|c|}{$\begin{array}{l}2 \text { phases - } 2 \text { successive } \\
\text { collection baths }\end{array}$} \\
\hline & $\begin{array}{l}\text { Description of phases } \\
\text { or steps }\end{array}$ & $\begin{array}{l}\text { Phase } \\
1\end{array}$ & $\begin{array}{l}\mathrm{CaCl}_{2}(15 \mathrm{wt} \%) \text { in } \mathrm{n}- \\
\text { decanol }\end{array}$ & $\begin{array}{l}\mathrm{CaCl}_{2} \\
(0.1-1 \mathrm{wt} \%)\end{array}$ & $\begin{array}{l}\text { Step } \\
1\end{array}$ & $\begin{array}{l}\text { DMC and evaporation } \\
\text { of DMC }\end{array}$ \\
\hline & & $\begin{array}{l}\text { Phase } \\
2\end{array}$ & $\begin{array}{l}\mathrm{Ba}\left(\mathrm{CH}_{3} \mathrm{COO}\right)_{2}(15 \\
\text { wt } \%) \\
\text { in water and } \\
\text { glycerol }\end{array}$ & & $\begin{array}{l}\text { Step } \\
2\end{array}$ & $\begin{array}{l}\mathrm{CaCl}_{2}(0.5-10 \mathrm{wt} \%) \text { in } \\
\text { water }\end{array}$ \\
\hline & Surfactant & \multicolumn{2}{|c|}{ Span 80} & NO & \multicolumn{2}{|l|}{ NO } \\
\hline
\end{tabular}



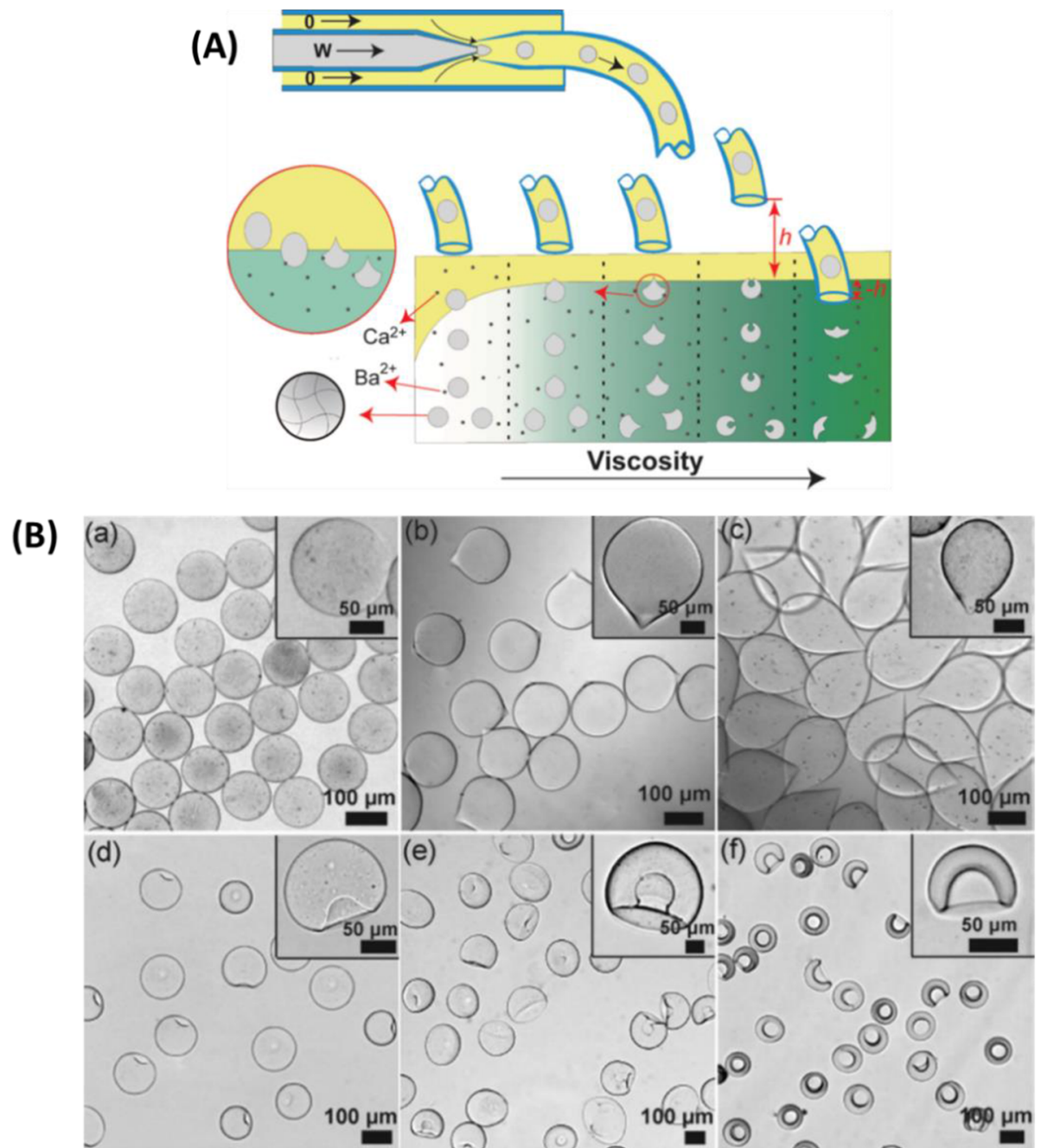

Fig. 18 A Schematic diagram of the preparation of Ca-alginate hydrogel microparticles using a microfluidic device constructed with glass capillaries, and off-chip gelation in a two-phase gelation bath. B Micrographs of Ca-alginate hydrogel microparticles of different shapes prepared under different experimental conditions. Figure reprinted with permission from Reference [20]

sufficient gelation. However, in practice, when and how to replenish them remains an issue.

To avoid the problem of replenishing the bath with the two cations, we collected Na-alginate droplets in an aqueous solution containing $\mathrm{CaCl}_{2}$ (Fig. 19a) without pre-gelation. Na-alginate $(0.006-1 \mathrm{wt} \%)$ droplets were first generated in DMC in a T-junction and Teflon-like capillaries (IDEX Health and Science), without using surfactant [59]. Because water is slightly soluble in DMC, $3 \mathrm{wt} \%$, water diffused gradually from droplets into DMC, causing the droplets to shrink as they passed through the channel (point A to B in Fig. 19a). Thus, droplet size reduced to below $100 \mu \mathrm{m}$. Furthermore, since alginate dissolution in the continuous fluid is negligible [39], with the loss of water, the alginate concentration in droplets increased. Then, the channel outlet (point B in Fig. 19a) was immersed in an aqueous solution of $\mathrm{CaCl}_{2}(0.1-1 \mathrm{wt} \%)$. An interface was created at the channel outlet (Fig. 19b) because of the non-total miscibility between DMC and water. Na-alginate droplets passed through the interface and entered the $\mathrm{CaCl}_{2}$ solution, leading to off-chip external gelation. After gelation, Ca-alginate hydrogel microparticles were dropletshaped (Fig. 19c) and tadpole-shaped (Fig. 19d), as in Fig. 18B, b-c. The shape of the microparticles varied with the flow rates, the concentration of $\mathrm{Na}$-alginate and that of $\mathrm{CaCl}_{2}$. It is likely that the deformation mechanism involved the forces applied to droplets at the interface, as explained by $\mathrm{Hu}$ et al. [20].

To improve the spherical shape of microparticles, we collected droplets in a bath of the continuous fluid, i.e., DMC. Hence, the droplets continued to shrink and were finally transformed into spherical condensed $\mathrm{Na}$-alginate microparticles, not yet gelated. For the gelation of the 


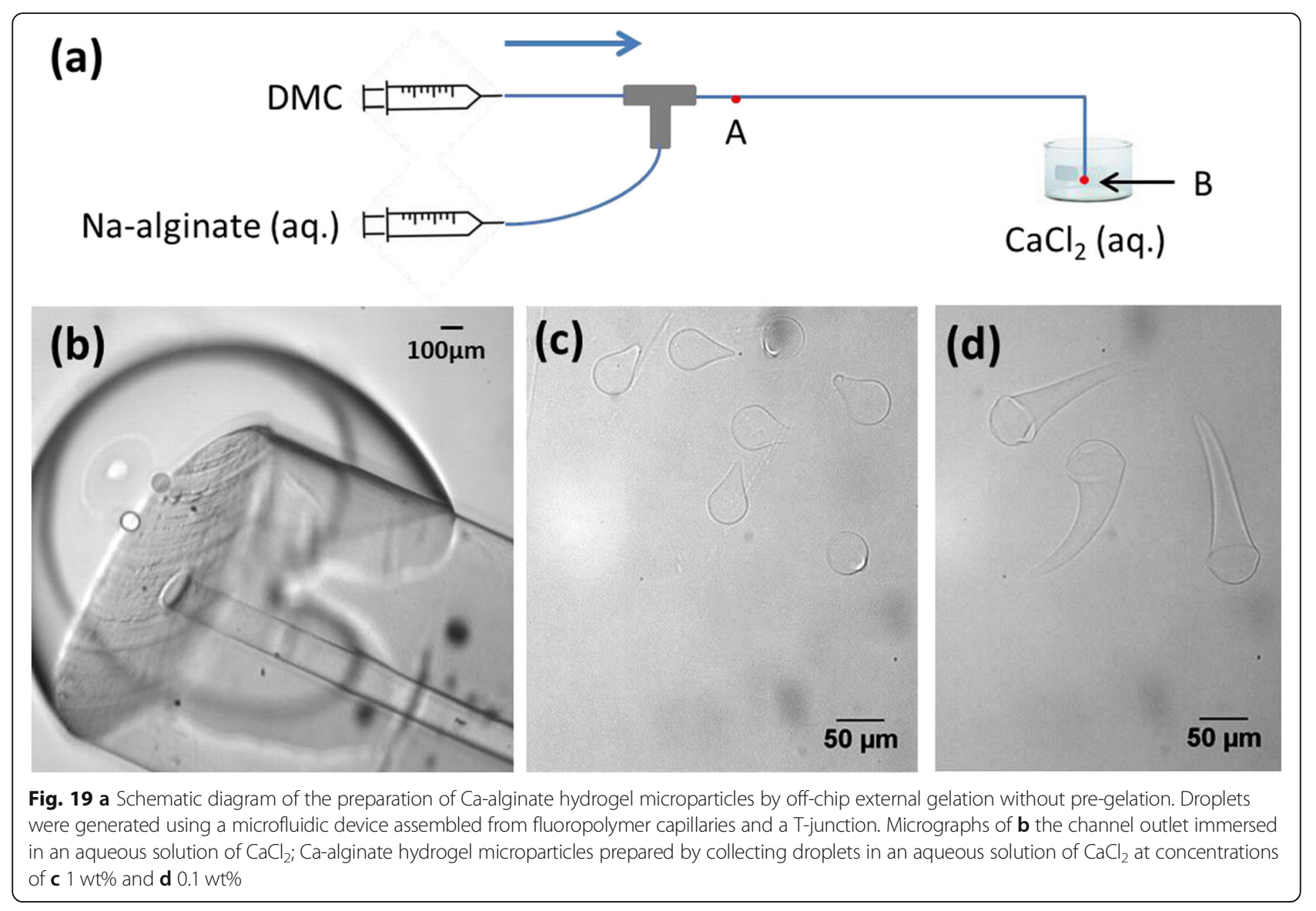

microparticles, the bath of DMC was first evaporated. Then, an aqueous solution of $\mathrm{CaCl}_{2}(0.5-10 \mathrm{wt} \%)$ was added to the dried $\mathrm{Na}$-alginate microparticles, inducing off-chip external gelation. Observations showed that this process was accompanied by the swelling of the microparticles without deformation (Fig. 20b-c). In the end, spherical Ca-alginate hydrogel microparticles were obtained. They were insoluble in water, indicating efficient gelation. Moreover, the concentration of $\mathrm{CaCl}_{2}$ had no significant effect on the size of the Ca-alginate microparticles. Since no surfactant is used in this method, no surfactant-removing step is needed, which simplifies the process. However, the quantity of microparticles produced is limited by the need to avoid droplet coalescence.

In conclusion, external gelation of alginate can be performed both on-chip and off-chip. For on-chip external gelation (Table 4), cross-linkers can be added to the continuous fluid, i.e., the oil. However, only limited concentrations can be used, since most are slightly soluble in oil. Therefore, introducing cross-linkers in emulsion form increases the quantity of alginate available for gelation. However, the particles are large and deformed. On the other hand, if partially miscible fluids are used, an aqueous solution of cross-linkers can be injected after droplet shrinkage. Particle size is reduced but the gelation is too rapid. Things can be improved by dissolving cross-linkers in an oil-based emulsion, introduced in small quantities but repeatedly.

For off-chip external gelation (Table 5), cross-linkers are introduced into the collection bath. A two-phase collection bath permits pre-gelation of Na-alginate droplets before gelation. However, the particles are large. Droplet size can be reduced to below the channel diameter by using partially miscible fluids for droplet generation, and the droplets can then be collected directly in the dispersed phase containing the cross-linker. However, the microparticles are deformed. To further reduce particle size and improve gelation, our solution is to perform two-step collection. Thus, off-chip external gelation can be used to produce shape-controlled and size-controlled microparticles.

\section{Properties of alginate hydrogel microparticles}

After preparation, alginate hydrogel microparticles should be characterized to obtain better knowledge of their properties, which will determine their further applications. This section discusses characterization approaches and factors influencing particle properties. 


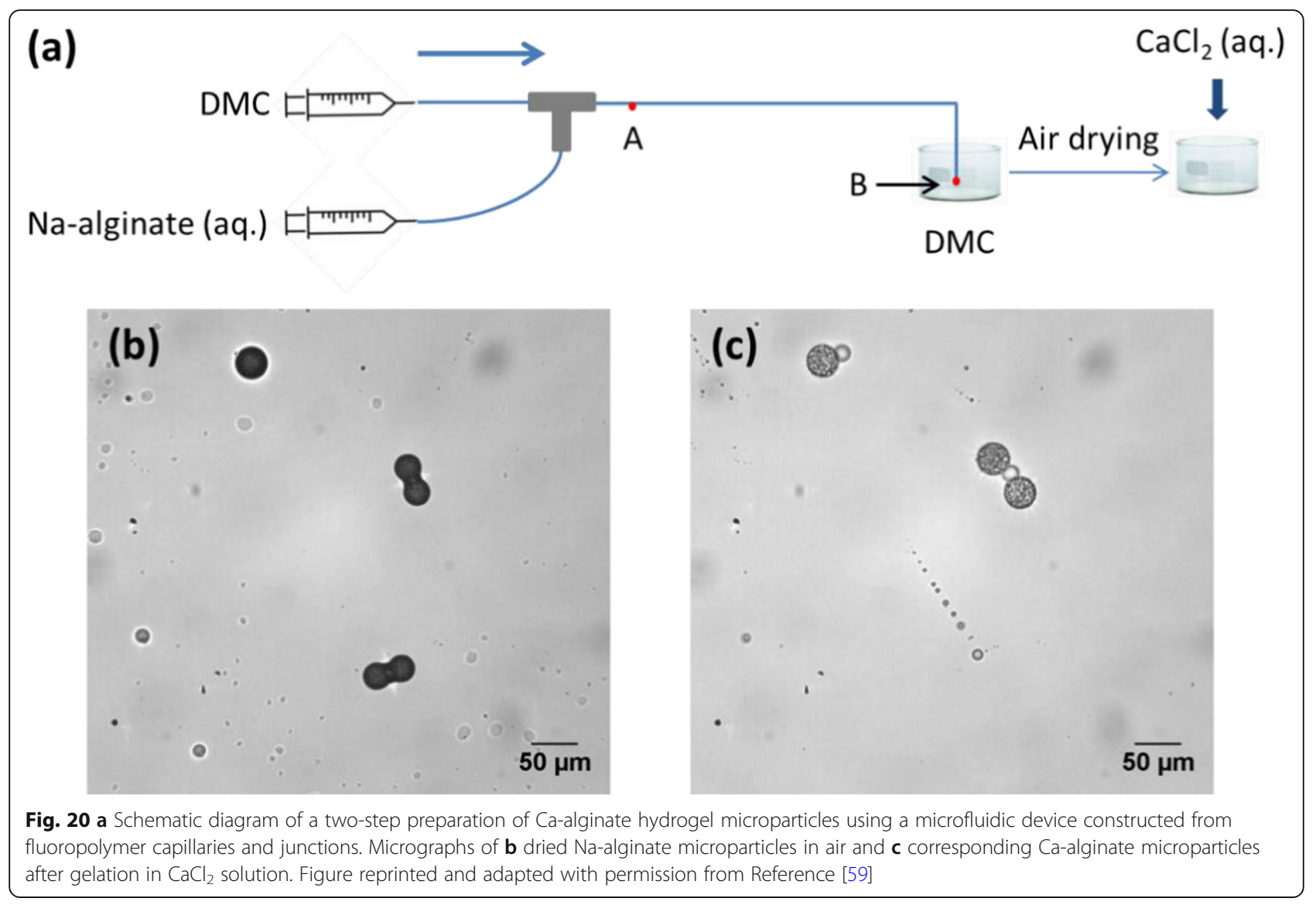

Table 6 Average size of alginate microparticles prepared using droplet-based microfluidics with different gelation methods

\begin{tabular}{|c|c|c|}
\hline Average size of microparticles & Gelation method & Reference \\
\hline $\begin{array}{l}1-50 \mu \mathrm{m} \\
10-300 \mathrm{~nm}\end{array}$ & $\begin{array}{l}\text { Internal gelation with water-soluble cross-linkers mixed } \\
\text { with Na-alginate before droplet generation }\end{array}$ & Rondeau and Cooper-White $2008^{\mathrm{a}}$ [39] \\
\hline $50-300 \mu \mathrm{m}$ & \multirow{3}{*}{$\begin{array}{l}\text { Internal gelation with water-soluble cross-linkers mixed } \\
\text { with Na-alginate after droplet generation }\end{array}$} & Xu et al. 2008 [54] \\
\hline $20-50 \mu \mathrm{m}$ & & Liu et al. 2006 [28] \\
\hline $22-42 \mu \mathrm{m}$ & & Trivedi et al. 2009 [48] \\
\hline 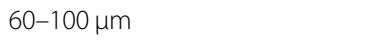 & \multirow{3}{*}{$\begin{array}{l}\text { Internal gelation with water-insoluble cross-linkers mixed } \\
\text { with Na-alginate after droplet generation }\end{array}$} & Zhang et al. 2007 [61] \\
\hline $26 \mu \mathrm{m}$ & & Akbari and Pirbodaghi 2014 [3] \\
\hline $50-100 \mu \mathrm{m}$ & & Yu et al. 2019 [56] \\
\hline $10-50 \mu \mathrm{m}$ & $\begin{array}{l}\text { Internal gelation with slightly water-soluble cross-linkers mixed } \\
\text { with Na-alginate after droplet generation }\end{array}$ & Utech et al. 2015 [49] \\
\hline $50-70 \mu \mathrm{m}$ & \multirow[t]{4}{*}{ External gelation with on-chip introduction of cross-linkers } & Zhang et al. 2007 [61] \\
\hline $147-176 \mu \mathrm{m}$ & & Liu et al. 2019 [29] \\
\hline $5-10 \mu \mathrm{m}$ & & Pittermannová et al. 2016 [34] \\
\hline $6-10 \mu \mathrm{m}$ & & Sugaya et al. $2011^{\mathrm{a}}[44]$ \\
\hline $100-200 \mu \mathrm{m}$ & \multirow[t]{2}{*}{ External gelation with off-chip introduction of cross-linkers } & Hu et al. 2012 [20] \\
\hline $7-40 \mu \mathrm{m}$ & & Zhang et al. 2020ª [59] \\
\hline
\end{tabular}


Size

Size is one of the most important properties of alginate hydrogel microparticles. For example, in drug delivery, microparticle size and size distribution affect drug release kinetics [50]. Size can be measured by optical or light-scattering (sub-micrometer range) microscopy [21], or using microgrippers [58].

Droplet-based microfluidics allows monodisperse microparticles to be produced with accurate control of size and size distribution. Table 6 shows the average size attained under droplet-based microfluidics using different gelation methods.

Figure 21 shows an example of the narrow size distribution of $\mathrm{Na}$-alginate and $\mathrm{Ca}$-alginate microparticles produced by droplet-based microfluidics [59] (part III.2.2.), indicating the monodispersity of the particle size. This is an advantage compared to conventional emulsification, which yields a broader size distribution [55].

With droplet-based microfluidics, the size of alginate hydrogel microparticles is influenced by several factors linked to the fluids used to generate them. When immiscible fluids are used for the dispersed and the continuous fluids, the size of alginate hydrogel microparticles is completely dependent on the size of the droplets first generated. Droplet size is influenced by channel size, and smaller droplets can be generated by using narrower channels. Other important factors are flow rates, alginate concentration [39, 59], and fluid viscosities [41, 46]. However, reducing channel size increases hydraulic resistance, as well as the pressure required to generate droplets. Moreover, it should be noted that in most cases, the $\mathrm{Na}$-alginate solution used is relatively viscous. Therefore, high pressure may cause leakage or even destruction of the microfluidic device [3, 49]. Thus, even when channel diameter is decreased and/or the flow rate of the continuous fluid is increased, producing droplets of a diameter below $10 \mu \mathrm{m}$ remains challenging.

Droplets of this size, below $10 \mu \mathrm{m}$, can be obtained without applying high pressure (Table 6), by using partially miscible fluids with low solubility in each other $[39,44,59]$. The dispersed fluid is an aqueous solution containing $\mathrm{Na}$-alginate; the continuous fluid is an organic solvent that is partially miscible with water and in which water has low solubility. The partial miscibility between the continuous and the dispersed fluids should be slight enough so that interfacial energy $\gamma_{C D}$ still allows the generation of droplets. The low solubility of water in the continuous fluid allows water diffusion from droplets into it, causing the droplets to shrink. As a result, the initially obtained diluted large droplets are transformed into concentrated small droplets or microparticles. Thus, their size is no longer dependent on the size of droplets initially generated but varies with the interaction between water and the continuous fluid.

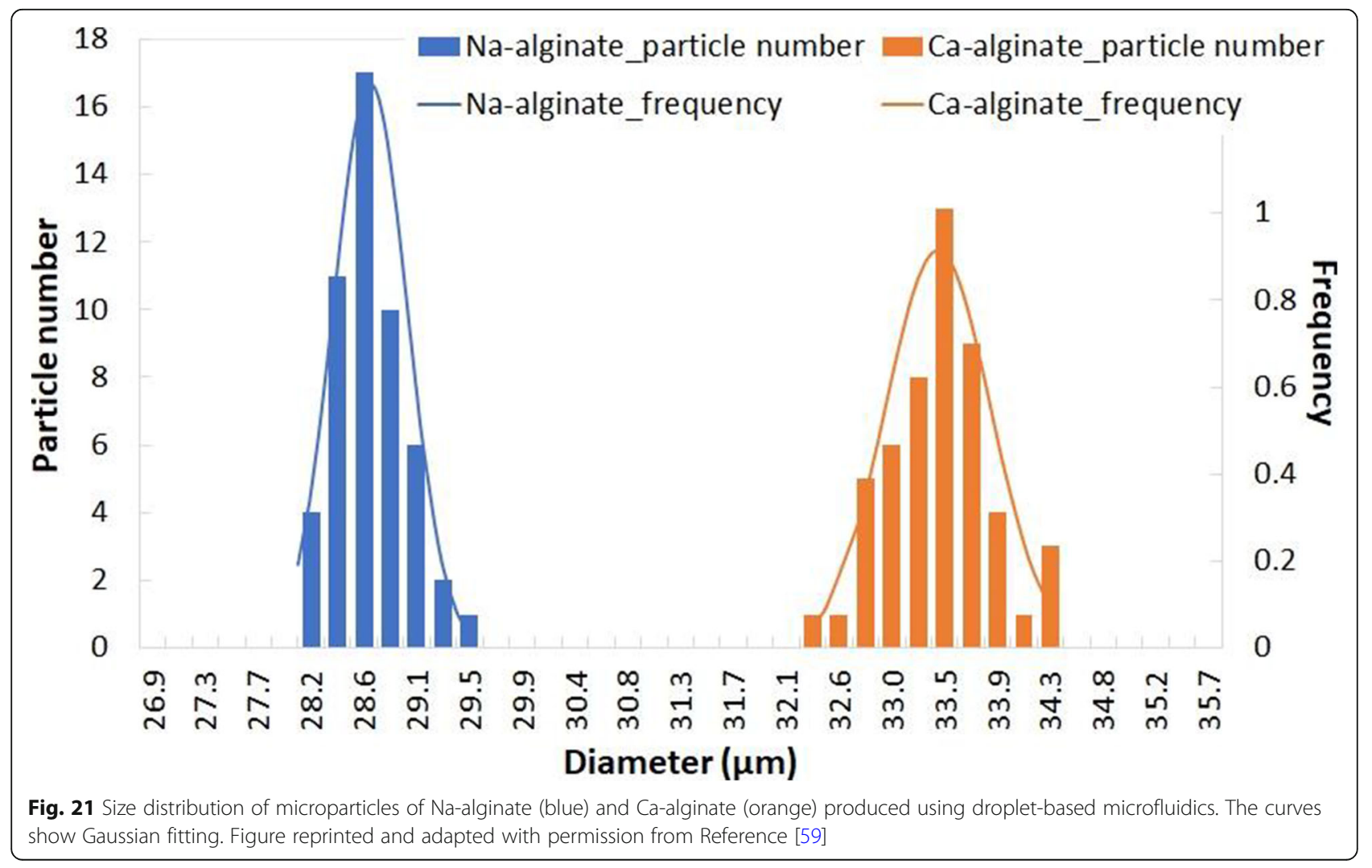




\section{Shape}

The shape of microparticles is another important property. A specific shape is sometimes needed; for example, red blood cell-mimicking microparticles are often required in a biconcave shape [32]. In drug delivery, the shape of microparticles has an impact on the drugrelease profile [13]. The overall shape of microparticles can be observed by using optical microscopy. Confocal microscopy of fluorescent samples can be used to form a spatial 3D image [21]. Better resolution can be obtained by using atomic force microscopy (AFM) or scanning electron microscopy (SEM) [59].

With droplet-based microfluidics, the spherical droplets initially generated can be transformed into spherical alginate hydrogel microparticles after gelation. Nonspherical microparticles can also be obtained. For example, as presented previously, Liu et al. first generated droplets of Na-alginate and $\mathrm{CaCl}_{2}$ separately [28]. Then the droplets were fused in a specifically designed microfluidic device, leading to gelation. By varying the channel geometry and controlling the flow rates of fluids, $\mathrm{Ca}$ alginate microparticles of different shapes were obtained (Fig. 10f). A different method was presented by $\mathrm{Hu}$ et al. [20] Na-alginate droplets were first generated and then collected in a two-phase gelation bath. Spherical droplets were deformed via interfacial energy derived from surfactant and viscous force. Thus, different shapes were produced (Fig. 18B) by controlling the surfactant used and the viscosity of the gelation bath.

\section{Concentration}

After preparation, the concentration of alginate in the microparticles can be calculated approximately. For instance, Zhang et al. used partially miscible fluids [59]. An aqueous solution of $\mathrm{Na}$-alginate was prepared with a known concentration. After droplet generation, droplet shrinkage occurred during passage through the channel due to water diffusion into the continuous fluid. Droplets were hence transformed into microparticles. As the diffusion of Na-alginate into the continuous fluid is negligible [39], the quantity of Na-alginate is constant. It can be calculated by multiplying the droplet volume and initial concentration. Finally, by measuring microparticle size, the concentration of Na-alginate can be calculated. The final concentration of $\mathrm{Na}$-alginate varies from 20 to $100 \mathrm{wt} \%$, depending on the initial concentration and diameter of the droplets generated [59]. Furthermore, as presented in Utech et al., the homogeneity of composition of microparticles can be determined with the help of fluorescence technology [49].

\section{Stability}

In most cases, surfactant is added in the continuous fluid $[48,49,61]$ to lower interfacial energy between the continuous and the dispersed fluids $\gamma_{\mathbf{C D}}$. Note that for each of the above studies, use or non-use of surfactant is mentioned when indicated by the authors (Tables 1,2 , $3,4,5)$. Surfactant facilitates the creation of a new interface, and thus the formation of droplets. It also stabilizes the formed droplets by preventing their coalescence [41]. Before the application of microparticles, the surfactant should be dissolved [3], except for biocompatible surfactant [49], although protocols for removing surfactant are rarely reported in the literature. To remove the oil used during the preparation, microparticles should be washed several times with an aqueous solution, followed by centrifugation [61].

However, despite its advantages, the use of surfactant may be undesirable. Surfactant has been shown to impact the surface properties of microparticles, such as morphology [45] and surface hydrophobicity [22]. Additionally, if rinsing is insufficient, the traces of surfactant on microparticles can damage the devices during application. In this situation, microparticles should be prepared without surfactant, which is possible with dropletbased microfluidics. In the microchannel, the coalescence of droplets can be avoided by enlarging the distance between droplets, which can be achieved by regulating flow rates. Furthermore, gelation, either onchip or off-chip, solidifies droplets and thus helps to avoid coalescence as well. Another strategy consists of using partially miscible fluids. This means that the droplets shrink and become more and more condensed during passage through the channel. At the outlet, either gelation [39] or a final shrinkage [59] can help avoid coalescence.

Moreover, for their stability, alginate hydrogel microparticles should be insoluble in water. This can be achieved by adopting proper gelation methods using a sufficient quantity of cross-linkers for effective gelation.

\section{Mechanical properties}

Mechanical properties of alginate hydrogel microparticles are usually characterized by measuring the Young's modulus, which varies with several factors. According to the type of bond between alginate and cross-linkers, covalent crosslinking results in a higher Young's modulus than ionic crosslinking in microparticles [6]. For ionic crosslinking, different cations present different affinities, i.e. different forces with alginate, thus different Young's moduli [33]. In addition, the Young's modulus increases with the concentration of alginate [31]. To measure the Young's modulus of a microparticle, it needs to be deformed under a known force, which can be either compressive or tensile [17]. The techniques used in the literature include micropipette aspiration [23], compression $[7,52]$ or Atomic Force Microscopy (AFM) [59, 61]. 


\section{Micropipette aspiration technique}

In the micropipette aspiration technique, controlled pressure is used to pull on the sample surface. When this pressure is high enough, the sample behaves like a viscoelastic fluid flowing inside the micropipette [17]. With a known pressure applied, the Young's modulus is calculated by applying the homogenous half-space model as described by Kleinberger et al. [23].

\section{Compression technique}

This technique consists in compressing a microparticle between two parallel plates [7] or between the flat end of a glass fiber and a glass surface [52]. A force transducer is connected to the equipment to measure the force applied. By varying the force, microparticle deformation can be recorded. Finally, according to the force-deformation curve and equations based on theoretical models, the Young's modulus is calculated.

However, both the micropipette aspiration technique and the compression technique are unsuitable for microparticles with high resistance to deformation, like the $\mathrm{Na}$ - and $\mathrm{Ca}$-alginate microparticles generated by Zhang et al. [59]. In this case, Atomic Force Microscopy was used to measure resistance to deformation.

\section{Atomic force microscopy}

Measurement of the Young's modulus of a microparticle with Atomic Force Microscopy (AFM) involves indenting it. The indentation depth (order of $100 \mathrm{~nm}$ ) is generally about 100 times less than the diameter of the microparticle (order of $10 \mu \mathrm{m}$ ). Hence the Young's modulus represents the local mechanical property on the surface, depending on the measuring point, as in Zhang et al. [59]. As the surface of their microparticles was smooth, variation in the local mechanical property was explained by the porous inner structure observed by Scanning Electron Microscopy (SEM) (Fig. 22).

\section{Conclusion}

This review focuses on the preparation of alginate hydrogel microparticles via droplet-based microfluidics. Various strategies are presented and classified within categories that represent the full range of methods used in the literature. Thus, readers will find that any strategy encountered can fit into one of the categories we present here.

To summarize, gelation is indispensable to transform alginate microdroplets into alginate hydrogel microparticles. It is realized by crosslinking, which requires crosslinkers to be introduced either inside or outside the microdroplets, causing respectively internal gelation or external gelation. For internal gelation, cross-linkers are introduced "on-chip" (in the microfluidic device). For external gelation, cross-linkers can be introduced both "on-chip" and/or "off-chip" (outside the microfluidic device). The review describes the various strategies applied under the microfluidic technique, and the size, shape, concentration, stability and mechanical properties of the alginate hydrogel microparticles obtained.

Lastly, we wish to stress the ease of constructing a microfluidic device with Fluoropolymer tubing and junctions compared to a chip, whatever its composition: PDMS, PMMA or glass. A microfluidic device's geometry can be tuned flexibly, whereas in a chip, the geometry of channels is fixed. Chip fabrication is laborious, time-consuming and expensive [12]. Clean room facilities are indispensable and the products used for the photolithography are toxic.

Thus, in terms of flexibility, cost and efficiency, we highly recommend using a microfluidic device with Fluoropolymer tubing and junctions, especially for proof-of-concept demonstrations.

\section{Outlook}

There is scope for several future improvements in the preparation of alginate hydrogel microparticles via droplet-based microfluidics.

1. When preparing microparticles using droplet-based microfluidics, surfactant is usually used. Unfortunately, surfactant has been shown to affect particle morphology [34]. Moreover, surfactant can damage the equipment involved in subsequent applications [59]. It obviously needs to be removed; however, the literature contains little information on how to remove surfactant. Moreover, despite its importance, the microparticle purifying process is barely touched on [34]. Future work could therefore usefully provide more details of the full preparation process, including surfactant removal.

2. In practice, a large number of microparticles usually needs to be produced. However, the throughput of microparticles fabricated by microfluidics is still limited. Exploring ways to scale up microparticle production would therefore be a welcome contribution.

3. Currently, most publications concern proof-ofconcepts or preliminary demonstrations. Little work is available on microparticles in real biological or biomedical applications [53]. Apart from biological barriers [35], the physiological environment is quite complex in terms of composition and rheological characteristics, which makes it extremely unlikely that microparticles can provide the functions required. The feasibility of using alginate hydrogel microparticles in real-life applications needs to be assessed. 

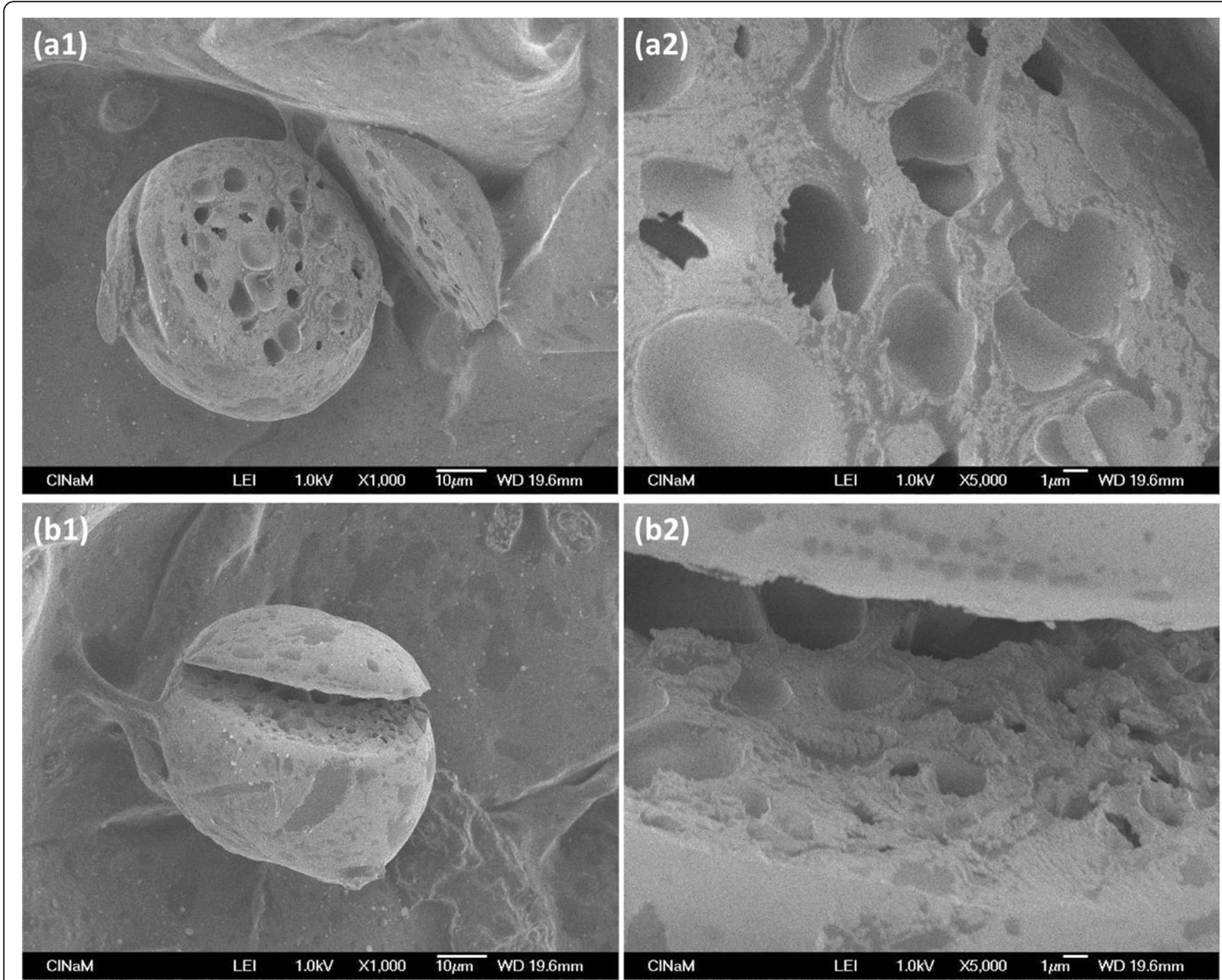

Fig. 22 SEM photographs of $2 \mathrm{Na}$-alginate microparticles (a) and (b), magnified 1000x (a1 and b1) and 5000x (a2 and b2). Na-alginate microparticles were prepared following the method mentioned in the publication [59]. Figure reprinted and adapted with permission from Reference [59]

4. The relation between degree of gelation and mechanical properties is rarely discussed in the literature. In fact, the degree of gelation itself is barely mentioned although, from a microscopic point of view, it influences mechanical properties. Thus, we believe it is worth assessing degree of gelation by measuring the concentration of crosslinkers inside the final hydrogel microparticles. Subsequently, the relation between degree of gelation and mechanical properties should also be addressed.

5. In practical applications, the surface of microparticles usually needs to be modified. For example, one way to detect antigens is to graft antibodies onto the surface of microparticles [38]. We note that the surface modification is always an extra step after the preparation of microparticles, thus complicating the process. The feasibility of an "all-in-one" process should be studied: can all the steps be performed within one single microfluidic device, combining microparticle production and surface modification?

\section{Acknowledgements}

We thank Marjorie Sweetko for English revision.

\section{Authors' contributions}

CZ, RG, NC and SV searched references and collected information. CZ and NC established the structure of whole manuscript. All authors wrote and reviewed the manuscript. All authors read and approved the final manuscript.

\section{Funding}

We are grateful to ANR CUMBA (ANR-15-CE19-0017-03) for its financial support.

Availability of data and materials Not applicable. 


\section{Declarations}

Ethics approval and consent to participate

Not applicable.

\section{Consent for publication}

Not applicable.

\section{Competing interests}

The authors declare no conflict of interest.

Received: 23 August 2021 Accepted: 6 November 2021

Published online: 24 November 2021

\section{References}

1. Agüero L, Zaldivar-Silva D, Peña L, Dias ML. Alginate microparticles as oral colon drug delivery device: a review. Carbohydr Polym. 2017;168:32-43. https://doi.org/10.1016/j.carbpol.2017.03.033.

2. Ahmed EM. Hydrogel: preparation, characterization, and applications: a review. J Adv Res. 2015;6(2):105-21. https://doi.org/10.1016/j.jare.2013.07. 006.

3. Akbari S, Pirbodaghi T. Microfluidic encapsulation of cells in alginate particles via an improved internal gelation approach. Microfluid Nanofluid. 2014;16(4):773-7. https://doi.org/10.1007/s10404-013-1264-z.

4. Barbieri M, Cellini F, Cacciotti I, Peterson SD, Porfiri M. In situ temperature sensing with fluorescent chitosan-coated PNIPAAm/alginate beads. J Mater Sci. 2017;52(20):12506-12. https://doi.org/10.1007/s10853-017-1345-6.

5. Baroud CN, Gallaire F, Dangla R. Dynamics of microfluidic droplets. Lab Chip. 2010;10(16):2032-45. https://doi.org/10.1039/c001191f.

6. Caccavo D, Cascone S, Lamberti G, Barba AA. Hydrogels: experimental characterization and mathematical modelling of their mechanical and diffusive behaviour. Chem Soc Rev. 2018;47(7):2357-73. https://doi.org/10.1 039/C7CS00638A.

7. Carin M, Barthès-Biesel D, Edwards-Lévy F, Postel C, Andrei DC. Compression of biocompatible liquid-filled HSA-alginate capsules: determination of the membrane mechanical properties. Biotechnol Bioeng. 2003;82(2):207-12. https://doi.org/10.1002/bit.10559.

8. Chan LW, Lee HY, Heng PWS. Production of alginate microspheres by internal gelation using an emulsification method. Int J Pharm. 2002;242(1-2): 259-62. https://doi.org/10.1016/S0378-5173(02)00170-9.

9. Christopher GF, Anna SL. Microfluidic methods for generating continuous droplet streams. J Phys D Appl Phys. 2007;40(19):R319-36. https://doi.org/1 0.1088/0022-3727/40/19/R01.

10. De Menech M, Garstecki P, Jousse F, Stone HA. Transition from squeezing to dripping in a microfluidic T-shaped junction. J Fluid Mech. 2008:595:141-61.

11. Draget Kl. 29 - alginates. In: Phillips GO, Williams PA, editors. Handbook of hydrocolloids. 2nd ed: Woodhead Publishing; 2009. p. 807-28. https://doi. org/10.1533/9781845695873.807.

12. Enck K, Rajan SP, Aleman J, Castagno S, Long E, Khalil F, et al. Design of an adhesive film-based microfluidic device for alginate hydrogel-based cell encapsulation. Ann Biomed Eng. 2020;48(3):1103-11. https://doi.org/10.1 007/s10439-020-02453-9.

13. Freiberg S, Zhu XX. Polymer microspheres for controlled drug release. Int J Pharm. 2004;282(1-2):1-18. https://doi.org/10.1016/j.ijpharm.2004.04.013.

14. Fundueanu G, Nastruzzi C, Carpov A, Desbrieres J, Rinaudo M. Physicochemical characterization of Ca-alginate microparticles produced with different methods. Biomaterials. 1999;20(15):1427-35. https://doi.org/10.101 6/S0142-9612(99)00050-2

15. Gacesa P. Alginates. Carbohydr Polym. 1988;8(3):161-82. https://doi.org/10.1 016/0144-8617(88)90001-X

16. Grant GT, Morris ER, Rees DA, Smith PJC, Thom D. Biological interactions between polysaccharides and divalent cations: the egg-box model. FEBS Lett. 1973;32(1):195-8. https://doi.org/10.1016/0014-5793(73)80770-7.

17. Guevorkian K, Maître JL. Chapter 10 - micropipette aspiration: a unique tool for exploring cell and tissue mechanics in vivo. In: Lecuit T, editor. Methods in cell biology: Academic Press; 2017. p. 187-201. https://doi.org/10.1016/bs. mcb.2016.11.012.

18. Haghgooie R, Toner M, Doyle PS. Squishy non-spherical hydrogel microparticles. Macromol Rapid Commun. 2010;31(2):128-34. https://doi. org/10.1002/marc.200900302.
19. Hoffman AS. Hydrogels for biomedical applications. Adv Drug Deliv Rev 2012;64:18-23. https://doi.org/10.1016/j.addr.2012.09.010

20. Hu Y, Wang Q, Wang J, Zhu J, Wang H, Yang Y. Shape controllable microge particles prepared by microfluidic combining external ionic crosslinking. Biomicrofluidics. 2012;6:026502. https://doi.org/10.1063/1.4720396.

21. Joye IJ, Mcclements DJ. Biopolymer-based nanoparticles and microparticles: fabrication, characterization, and application. Curr Opin Colloid Interface Sci. 2014;19(5):417-27. https://doi.org/10.1016/j.cocis.2014.07.002.

22. Kidane A, Guimond P, Rob Ju T-C, Sanchez M, Gibson J, North A, et al. Effects of cellulose derivatives and poly (ethylene oxide)-poly (propylene oxide) tri-block copolymers (Pluronic ${ }^{\oplus}$ surfactants) on the properties of alginate based microspheres and their interactions with phagocytic cells. J Control Release. 2002;85(1-3):181-9. https://doi.org/10.1016/S0168-3659(02 )00281-X.

23. Kleinberger RM, Burke NaD, Dalnoki-Veress K, Stöver HDH. Systematic study of alginate-based microcapsules by micropipette aspiration and confocal fluorescence microscopy. Mater Sci Eng C. 2013;33(7):4295-304. https://doi. org/10.1016/j.msec.2013.06.033.

24. Lee B-B, Ravindra P, Chan E-S. Size and shape of calcium alginate beads produced by extrusion dripping. Chem Eng Technol. 2013;36:1627-42. https://doi.org/10.1002/ceat.201300230.

25. Lee KY, Mooney DJ. Alginate: properties and biomedical applications. Prog Polym Sci. 2012;37(1):106-26. https://doi.org/10.1016/.jprogpolymsci.2011.06.003.

26. Lee KY, Yuk SH. Polymeric protein delivery systems. Prog Polym Sci. 2007; 32(7):669-97. https://doi.org/10.1016/j.progpolymsci.2007.04.001.

27. Li W, Zhang L, Ge X, Xu B, Zhang W, Qu L, et al. Microfluidic fabrication of microparticles for biomedical applications. Chem Soc Rev. 2018;47(15):564683. https://doi.org/10.1039/C7CS00263G.

28. Liu K, Ding H-J, Liu J, Chen Y, Zhao X-Z. Shape-controlled production of biodegradable calcium alginate gel microparticles using a novel microfluidic device. Langmuir. 2006;22(22):9453-7. https://doi.org/10.1021/la061729+

29. Liu Y, Tottori N, Nisisako T. Microfluidic synthesis of highly spherical calcium alginate hydrogels based on external gelation using an emulsion reactant. Sensors Actuators B Chem. 2019;283:802-9. https://doi.org/10.1016/j.snb.201 8.12.101.

30. Maitra J, Shukla V. Cross-linking in hydrogels - a review. Am J Polym Sci. 2014;4:25-31.

31. Markert CD, Guo X, Skardal A, Wang Z, Bharadwaj S, Zhang Y, et al. Characterizing the micro-scale elastic modulus of hydrogels for use in regenerative medicine. J Mech Behav Biomed Mater. 2013;27:115-27. https://doi.org/10.1016/j.jmbbm.2013.07.008.

32. Merkel TJ, Jones SW, Herlihy KP, Kersey FR, Shields AR, Napier M, et al. Using mechanobiological mimicry of red blood cells to extend circulation times of hydrogel microparticles. Proc Natl Acad Sci. 2011;108(2):586-91. https://doi. org/10.1073/pnas.1010013108.

33. Mørch ÝA, Donati I, Strand BL, Skjåk-Bræk G. Effect of Ca2+, Ba2+, and Sr2+ on alginate microbeads. Biomacromolecules. 2006;7(5):1471-80. https://doi. org/10.1021/bm060010d

34. Pittermannová A, Ruberová Z, Zadražil A, Bremond N, Bibette J, Štěpánek F. Microfluidic fabrication of composite hydrogel microparticles in the size range of blood cells. RSC Adv. 2016;6(105):103532-40. https://doi.org/10.1039/C6RA23003B.

35. Poon W, Kingston BR, Ouyang B, Ngo W, Chan WCW. A framework for designing delivery systems. Nat Nanotechnol. 2020;15(10):819-29. https:// doi.org/10.1038/s41565-020-0759-5.

36. Qiu C, Chen M, Yan H, Wu H. Generation of uniformly sized alginate microparticles for cell encapsulation by using a soft-lithography approach. Adv Mater. 2007;19(12):1603-7. https://doi.org/10.1002/adma.200602574.

37. Ren K, Zhou J, Wu H. Materials for microfluidic chip fabrication. Acc Chem Res. 2013;46(11):2396-406. https://doi.org/10.1021/ar300314s.

38. Roh YH, Lee HJ, Bong KW. Microfluidic fabrication of encoded hydrogel microparticles for application in multiplex immunoassay. BioChip J. 2019; 13(1):64-81. https://doi.org/10.1007/s13206-019-3104-z.

39. Rondeau E, Cooper-White JJ. Biopolymer microparticle and nanoparticle formation within a microfluidic device. Langmuir. 2008;24(13):6937-45. https://doi.org/10.1021/la703339u.

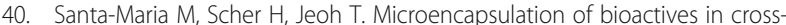
linked alginate matrices by spray drying. J Microencapsul. 2012;29(3):286-95. https://doi.org/10.3109/02652048.2011.651494.

41. Seemann R, Brinkmann M, Pfohl T, Herminghaus S. Droplet based microfluidics. Rep Prog Phys. 2011;75(1):016601. https://doi.org/10.1088/ 0034-4885/75/1/016601. 
42. Shikha S, Zheng X, Zhang Y. Upconversion nanoparticles-encoded hydrogel microbeads-based multiplexed protein detection. Nano-Micro Lett. 2018; 10(2):31. https://doi.org/10.1007/s40820-017-0184-y.

43. Stephenson R, Stuart J. Mutual binary solubilities: water-alcohols and water-esters. J Chem Eng Data. 1986;31(1):56-70. https:/doi.org/10.1021/je00043a019.

44. Sugaya S, Yamada M, Seki M. Production of extremely-small hydrogel microspheres by utilizing water-droplet dissolution in a polar solvent. In: Landers J, editor. 15th International Conference on Miniaturized Systems for Chemistry and Life Sciences. Seattle: Chemical and Biological Microsystems Society ( CBMS ); 2011. p. 18-20.

45. Sundberg DC, Casassa AP, Pantazopoulos J, Muscato MR, Kronberg B, Berg J. Morphology development of polymeric microparticles in aqueous dispersions. I. Thermodynamic considerations. J Appl Polym Sci. 1990;41(78): 1425-42. https://doi.org/10.1002/app.1990.070410706.

46. Teh SY, Lin R, Hung LH, Lee AP. Droplet microfluidics. Lab Chip. 2008;8(2): 198-220. https://doi.org/10.1039/b715524g.

47. Trivedi V, Doshi A, Kurup GK, Ereifej E, Vandevord PJ, Basu AS. A modular approach for the generation, storage, mixing, and detection of droplet libraries for high throughput screening. Lab Chip. 2010;10(18):2433-42. https://doi.org/10.1039/c004768f.

48. Trivedi V, Ereifej ES, Doshi A, Sehgal P, Vandevord PJ, Basu AS. Microfluidic encapsulation of cells in alginate capsules for high throughput screening, Proceedings of the 31st annual international conference of the IEEE engineering in medicine and biology society: engineering the future of biomedicine, EMBC 2009; 2009. p. 7037-40.

49. Utech S, Prodanovic R, Mao AS, Ostafe R, Mooney DJ, Weitz DA. Microfluidic generation of monodisperse, structurally homogeneous alginate microgels for cell encapsulation and 3D cell culture. Adv Healthc Mater. 2015;4(11): 1628-33. https://doi.org/10.1002/adhm.201500021.

50. Uyen NTT, Hamid ZaA, Tram NXT, Ahmad N. Fabrication of alginate microspheres for drug delivery: a review. Int J Biol Macromol. 2020;153: 1035-46. https://doi.org/10.1016/j.ijbiomac.2019.10.233.

51. Velings NM, Mestdagh MM. Physico-chemical properties of alginate gel beads. Polym Gels Netw. 1995;3(3):311-30. https://doi.org/10.1016/09667822(94)00043-7.

52. Wang CX, Cowen C, Zhang Z, Thomas CR. High-speed compression of single alginate microspheres. Chem Eng Sci. 2005;60(23):6649-57. https:// doi.org/10.1016/j.ces.2005.05.052

53. Wang W, Zhou C. A journey of nanomotors for targeted cancer therapy: principles, challenges, and a critical review of the state-of-the-art. Adv Healthc Mater. 2020;10:e2001236.

54. Xu JH, Li SW, Tan J, Luo GS. Controllable preparation of monodispersed calcium alginate microbeads in a novel microfluidic system. Chem Eng Technol. 2008;31(8):1223-6. https://doi.org/10.1002/ceat.200800027.

55. Xu Q, Hashimoto M, Dang TT, Hoare T, Kohane DS, Whitesides GM, et al. Preparation of monodisperse biodegradable polymer microparticles using a microfluidic flow-focusing device for controlled drug delivery. Small. 2009; 5(13):1575-81. https://doi.org/10.1002/smll.200801855.

56. Yu L, Sun Q, Hui Y, Seth A, Petrovsky N, Zhao C-X. Microfluidic formation of core-shell alginate microparticles for protein encapsulation and controlled release. J Colloid Interface Sci. 2019;539:497-503. https://doi.org/10.1016/j. jcis.2018.12.075.

57. Zagnoni M, Anderson J, Cooper JM. Hysteresis in multiphase microfluidics at a T-junction. Langmuir. 2010;26(12):9416-22. https://doi.org/10.1021/la1 004243.

58. Zhang C. Development of a microfluidic method for the preparation of mimetic microparticles of red blood cells with controllable size and mechanical properties: Université d'Aix-Marseille; 2020. https://tel.archivesouvertes.fr/tel-02474896.

59. Zhang C, Grossier R, Lacaria L, Rico F, Candoni N, Veesler S. A microfluidic method generating monodispersed microparticles with controllable sizes and mechanical properties. Chem Eng Sci. 2020;211:115322. https://doi. org/10.1016/j.ces.2019.115322.

60. Zhang H, Tumarkin E, Peerani R, Nie Z, Sullan RMA, Walker GC, et al. Microfluidic production of biopolymer microcapsules with controlled morphology. J Am Chem Soc. 2006;128(37):12205-10. https://doi.org/10.1 021/ja0635682.

61. Zhang H, Tumarkin E, Sullan RMA, Walker GC, Kumacheva E. Exploring microfluidic routes to microgels of biological polymers. Macromol Rapid Commun. 2007;28(5):527-38. https://doi.org/10.1002/marc.200600776.
62. Zhang J, Shikha S, Mei Q, Liu J, Zhang Y. Fluorescent microbeads for pointof-care testing: a review. Microchim Acta. 2019;186(6):361. https://doi.org/1 0.1007/s00604-019-3449-y.

63. Zhang S, Guivier-Curien C, Veesler S, Candoni N. Prediction of sizes and frequencies of nanoliter-sized droplets in cylindrical T-junction microfluidics. Chem Eng Sci. 2015;138:128-39. https://doi.org/10.1016/j.ces.2015.07.046.

64. Zhao X, Cui Y, He Y, Wang S, Wang J. Synthesis of multi-mode quantum dots encoded molecularly imprinted polymers microspheres and application in quantitative detection for dopamine. Sensors Actuators B Chem. 2020;304:127265. https://doi.org/10.1016/j.snb.2019.127265.

65. Zhu P, Wang L. Passive and active droplet generation with microfluidics: a review. Lab Chip. 2017;17(1):34-75. https://doi.org/10.1039/C6LC01018K.

\section{Publisher's Note}

Springer Nature remains neutral with regard to jurisdictional claims in published maps and institutional affiliations.
Ready to submit your research? Choose BMC and benefit from:

- fast, convenient online submission

- thorough peer review by experienced researchers in your field

- rapid publication on acceptance

- support for research data, including large and complex data types

- gold Open Access which fosters wider collaboration and increased citations

- maximum visibility for your research: over $100 \mathrm{M}$ website views per year

At BMC, research is always in progress.

Learn more biomedcentral.com/submissions 